Article

\title{
Removal of ZnO Nanoparticles from Natural Waters by Coagulation-Flocculation Process: Influence of Surfactant Type on Aggregation, Dissolution and Colloidal Stability
}

\author{
Rizwan Khan ${ }^{1}\left(\mathbb{D}\right.$, Muhammad Ali Inam ${ }^{1}\left(\mathbb{D}\right.$, Muhammad Mazhar Iqbal ${ }^{1}($, \\ Muhammad Shoaib ${ }^{1}{ }^{\circledR}$, Du Ri Park ${ }^{1}{ }^{\circledR}$, Kang Hoon Lee ${ }^{2}{ }^{\circledR}$, Sookyo Shin ${ }^{1}$, Sarfaraz Khan ${ }^{3}$ and \\ Ick Tae Yeom ${ }^{1, *}$ \\ 1 Graduate School of Water Resources, Sungkyunkwan University (SKKU) 2066, Suwon 16419, Korea; \\ rizwankhan@skku.edu (R.K.); aliinam@skku.edu (M.A.I.); mazhar0559@skku.edu (M.M.I.); \\ changezi@skku.edu (M.S.); enfl8709@skku.edu (D.R.P.); tkssk08@gmail.com (S.S.) \\ 2 Center for Built Environment, Sungkyunkwan University, (SKKU) 2066, Suwon 16419, Korea; \\ diasyong86@gmail.com \\ 3 Key Laboratory of the Three Gorges Reservoir Region Eco-Environment, State Ministry of Education, \\ Chongqing University, Chongqing 400045, China; Sfk.jadoon@yahoo.com \\ * Correspondence: yeom@skku.edu
}

Received: 30 November 2018; Accepted: 19 December 2018; Published: 20 December 2018

check for updates

\begin{abstract}
The zinc oxide nanoparticles (ZnO NPs) and surfactants that are widely used in commercial and industrial products lead to the likelihood of their co-occurrence in natural water, making it essential to investigate the effect of surfactants on the fate and mobility of ZnO NPs. The present study seeks to elucidate the effect of an anionic sodium dodecyl sulfate (SDS) and a nonionic nonylphenol ethoxylate (NPEO), on ZnO NPs adsorption, aggregation, dissolution, and removal by the coagulation process. The results indicate that the presence of SDS in ZnO NPs suspension significantly reduced the $\zeta$-potential and hydrodynamic diameter (HDD), while the effect of NPEO was found not to be significant. The sorption of SDS and NPEO by ZnO NPs were fitted with Langmuir model, but the Freundlich isotherm was more suitable for SDS at $\mathrm{pH}$ 9.0. Moreover, the adsorption was strongly $\mathrm{pH}$-dependent due to the formation of mono-bilayer patches onto the NPs. The SDS remarkably affect the dissolution and aggregation phenomena of ZnO NPs in natural waters as compared to NPEO. Finally, the coagulation results showed that the removal efficiency of $\mathrm{ZnO}, \mathrm{Zn}^{2+}$ and the surfactant in synthetic and wastewaters at optimum ferric chloride (FC) dosage reached around $85-98 \%$ and $20-50 \%$, respectively. Coagulation mechanism investigation demonstrated that the cooperation of charge neutralization and adsorptive micellar flocculation (AMF) might play an important role. In summary, this study may provide new insight into the environmental behavior of coexisting ZnO NPs and surfactants in water treatment processes, and it may facilitate their sustainable use in commercial products and processes.
\end{abstract}

Keywords: adsorption; aggregation; coagulation; dissolution; surfactants; wastewater treatment; $\mathrm{ZnO}$ NPs

\section{Introduction}

Zinc oxide nanoparticles ( $\mathrm{ZnO} \mathrm{NPs}$ ) are used in various industrial applications, such as material sciences, environmental remediation, cosmetics, medicine, foods, and biosensors [1]. The annual production of $\mathrm{ZnO} N P s$ is estimated to be $(31,500-34,000 \mathrm{t} / \mathrm{y})$, which is anticipated to increase over time. 
It has been demonstrated that around $10-25 \%$ of produced ZnO NPs may release into the environment and enter freshwater sources [2,3]. A recent study [3] has reported the ZnO NPs concentration up to $0.05-10 \mu \mathrm{g} / \mathrm{L}$ in United States (U.S) surface waters; thus, NPs accumulate in aquatic organisms and may consequently cause undesirable environmental and health risks. Several studies $[4,5]$ have reported the toxicity of ZnO NPs to aquatic organisms, such as bacteria, algae, cladocerans, soil organisms, rotifers, fish, and daphnia. Moreover, the genotoxicity of NPs in human mesenchymal stem cells has been demonstrated in previous studies as well $[5,6]$. The Zn-based NPs can penetrate the cells and it may cause DNA fragmentations as well as chromosomal aberrations. Thus, environmental transportation and transformation of ZnO NPs in the water matrices are essential to be studied in order to control the associated potential environmental risks.

When $\mathrm{ZnO}$ NPs are released into aquatic environments, their transport within the system depends on multiple environmental aspects as well as physiochemical properties (i.e., size, shape, concentration, solubility). Some studies $[7,8]$ recently reported that factors, such as $\mathrm{pH}$, dissolved organic matter (DOM), electrolyte type, and ionic strength (IS) significantly affect the NPs agglomeration process. The $\mathrm{ZnO}$ NPs is stable at $\mathrm{pH}$ value between 6.5 to 8.5 , while the higher IS enhance the NPs destabilization with decreasing tendency in the order of $\mathrm{Ca}^{2+}>\mathrm{Mg}^{2+}>\mathrm{Na}^{+} \approx \mathrm{K}^{+}$[7]. The presence of DOM remarkably enhanced the stability of ZnO NPs due to the effect of steric hindrance and electrostatic repulsion [8]. It has been reported that ZnO NPs coated with DOM (humic and salicylic acid) hinders the removal of NPs during the coagulation process [9]. In addition, surfactants can typically be detected in municipal and industrial wastewater in concentrations ranging from 1-1000 mg/L [10,11]. The surfactants are harmful to the aquatic organism and humans, while they also affect the quality of water due to froth formation [12]. Besides their strong adsorption capacity, surfactants can form highly stable colloids in solution, even at low concentration, by lowering the interfacial surface tension. Therefore, the co-presence of ZnO NPs and surfactants in the system may alter their transportation behavior as well as increase their bioavailability in aqueous environments.

The nature of the interaction between the ZnO NPs and surfactants depends on environmental water matrices. The surfactants, such as Triton X-100 and dodecyl benzene sulfonate (SDBS), were found to inhibit the uncontrollable aggregation of titanium dioxide $\left(\mathrm{TiO}_{2}\right)$ by enhancing the electro steric repulsive forces between the NPs [13]. Xuankun Li showed that ionic sodium dodecyl sulfate (SDS) significantly reduce the aggregation of $\mathrm{TiO}_{2} \mathrm{NPs}$ and stabilize the colloidal suspension at higher concentration [14,15]. Moreover, it was also demonstrated that at $\mathrm{pH} 9.0$, increasing surfactant concentration led to the enhancement of transport distance of $\mathrm{TiO}_{2}$ in porous media $[15,16]$. The significant effect of low concentrations $(0.004 \%(\mathrm{w}: \mathrm{v}))$ of SDBS and cetyl trimethyl ammonium bromide (CTAB) was found on the retention and transport properties of graphene NPs in saturated porous media $[17,18]$. Some researchers [18] have used SDBS to disperse and stabilize several NPs to produce surfactant-solubilized NPs that were highly mobile in saturated sandy as well as porous media. Several functional groups of surfactants may readily be adsorbed on the ZnO NPs surface and affect the aggregation behaviors by changing the surface properties, thereby increasing the colloidal stability and release of $\mathrm{Zn}^{2+}$ ions in receiving water bodies [19]. Thus, it is important to explore the removal of $\mathrm{ZnO}$ NPs and potential surfactants ions from water to reduce the NPs associated environmental risks.

To date, many studies $[10,11,19,20]$ have focused on the effect of surfactant on the aggregation behaviors of NPs in simulated natural waters. To address the current limitations in knowledge regarding the effect of surfactants on ZnO NPs behavior in natural surface waters and its fundamental mechanism, we thoroughly studied the effect of two surfactants, i.e., anionic sodium dodecyl sulfate (SDS) and nonionic nonylphenol ethoxylates (NPEO), on the stability, dissolution, and sedimentation of $\mathrm{ZnO}$ in different aquatic chemistry conditions. In particular, the effects of SDS and NPEO on sorption ability and $\mathrm{ZnO}$ NPs stability at various $\mathrm{pH}$ ranges were assessed. In addition, we also studied the simultaneous removal of $\mathrm{ZnO} N P s, \mathrm{Zn}^{2+}$, and surfactants from synthetic as well as natural waters by coagulation. 


\section{Materials and Methods}

\subsection{Chemical Reagents}

The commercial ZnO nanopowder (CAS \# 1314-13-2) that was used in this study has a purity of 97\% with vendor reported transmission electron microscope (TEM) primary size (50 nm) Table 1 for detail properties; SDS (99\%) and NPEO (97\%) surfactants were procured from Sigma Aldrich (St. Louis, MO, USA). The iso-electric point (pHiep) of $\mathrm{ZnO}$ was determined, see details in Supplementary Material (SM) (Figure S2). Sodium hydroxide (NaOH), iron (III) chloride hexahydrate $\left(\mathrm{FeCl}_{3}-6 \mathrm{H}_{2} \mathrm{O}\right)$, and hydrochloric acid $(\mathrm{HCl})$ were procured from local suppliers. The Synergy water system (Milli-Q, Millipore, Burlington, MA, USA) was used to produce ultra-pure water and it was used in the preparations of the stock solutions as well as synthetic waters.

Table 1. Properties of zinc oxide nanoparticles (ZnO NPs) used in the current study.

\begin{tabular}{|c|c|c|c|}
\hline Nanomaterials Parameter & Unit & Technique & Value \\
\hline Manufacturer-reported size & $\mathrm{nm}$ & TEM & $<50$ \\
\hline Bulk Density & $\mathrm{g}\left(\mathrm{cm}^{3}\right)^{-1}$ & - & 5.60 \\
\hline Solubility & & & High \\
\hline BET specific surface area & $\mathrm{m}^{2} \mathrm{~g}^{-1}$ & BET & $12.2 \pm 0.4$ \\
\hline Iso-electric point ( $\mathrm{pH}$ iep, see Figure S2B) & - & & 9.2 \\
\hline Zeta potential in pure water (at $\mathrm{pH} 7)$ & $\mathrm{mV}$ & Zetasizer & $+14 \pm 2.1$ \\
\hline HDD measured in pure water $(n=50)$ & $\mathrm{nm}$ & DLS & $280 \pm 35$ \\
\hline $\begin{array}{c}\text { Purity/moisture content } \\
\text { (see Figure S1D) }\end{array}$ & wt. $\%$ & TGA/ICP-OES & $96.52 / 1.85$ \\
\hline Crystalline structure (Figure 1C) & - & XRD & Hexagonal \\
\hline Shape & & & Polyhedral roughly round \\
\hline Hamaker Constant & $\mathrm{J}$ & - & $1.9 \times 10^{-20}$ \\
\hline $\begin{array}{l}\text { Net energy barrier in pure water } \\
\text { (IS } 5 \times 10^{-6} \mathrm{M} \text { ) }\end{array}$ & $\mathrm{kT}^{(\mathrm{a})}$ & - & 42.8 \\
\hline
\end{tabular}

a $1 \mathrm{KT}=4.1142 \times 10-21 \mathrm{~J}$ at $25^{\circ} \mathrm{C}$.

\subsection{Preparation of NPS and Surfactants Stock Solutions}

First, $100 \mathrm{mg}$ of $\mathrm{ZnO}$ powder was weighed using a microbalance (Mettler Toledo Ag Model XP26DR) and dispersed into $1000 \mathrm{~mL}$ water. The dispersion was subjected to probe sonicate for a cycle of 30 min using an ultrasonicator (Bio safer 1200-90, $400 \mathrm{~W}, 20 \mathrm{kHz}, 40 \%$ amplitude-continuous mode, Nanjing, China). The properties of the surfactants that were used in this study are shown in Table 2, while $0.1 \%(\mathrm{w}: \mathrm{v})$ stock solutions of both surfactants were prepared in ultra-pure water. The coagulant stock solution, i.e., $0.1 \mathrm{M}$ ferric chloride (FC) concentration solution was prepared by dissolving a specific amount of $\mathrm{FeCl}_{3}-6 \mathrm{H}_{2} \mathrm{O}$ into the pure water. The stock solutions were kept in the dark at $4{ }^{\circ} \mathrm{C}$ before diluting it to the required experimental concentration.

Table 2. Properties of surfactants used in the present study.

\begin{tabular}{|c|c|c|c|}
\hline Surfactant Type & Formula & Structure & $\begin{array}{l}\text { Molecular Weight } \\
\text { (g/mol) }\end{array}$ \\
\hline $\begin{array}{c}\text { SDS } \\
\text { (Anionic) }\end{array}$ & $\mathrm{CH}_{3}\left(\mathrm{CH}_{2}\right)_{11} \mathrm{OSO}_{3} \mathrm{Na}$ & & 288.38 \\
\hline $\begin{array}{c}\text { NPEO } \\
\text { (Nonionic) }\end{array}$ & $\mathrm{C}_{9} \mathrm{H}_{19} \mathrm{C}_{6} \mathrm{H}_{4}\left(\mathrm{OCH}_{2} \mathrm{CH}_{2}\right)_{9} \mathrm{OH}$ & & 616.82 \\
\hline
\end{tabular}




\subsection{Preparation and Characteristic of Environmental Water Samples}

Six water samples were used to assess the impact of different surfactants on the environmental behavior of ZnO NPs. Four synthetic waters (W1-W4) with different concentrations of both surfactants were prepared in the lab, as shown in Table 3. The other two samples were tap water (TW) (Sungkyunkwan University, Suwon Campus, Gyeonggi-do, Korea). The wastewater (WW) samples was obtained from metal processing industry (LS-Nikko Copper Inc., Onsan National Industrial Complex, Ulsan, Korea). The wastewater sample was diluted to reduce the concentration of total organic carbon (TOC) and heavy metal ions. The details of several parameters are shown in Table S1.

Table 3. Characteristics of synthetic and environmental waters.

\begin{tabular}{|c|c|c|c|c|c|c|c|c|}
\hline \multirow{2}{*}{$\begin{array}{c}\text { Surfactant } \\
\text { Type }\end{array}$} & \multicolumn{2}{|c|}{$\begin{array}{l}\text { Concentration } \\
\text { (w:v) } \%\end{array}$} & \multirow{2}{*}{$\begin{array}{c}\text { Water Code } \\
\text { Control }\end{array}$} & \multirow{2}{*}{$\begin{array}{c}\begin{array}{c}\text { Released } \\
\mathbf{Z n}^{2+}(\mathbf{m g} / \mathbf{L})\end{array} \\
0.893 \pm 0.10\end{array}$} & \multirow{2}{*}{$\begin{array}{c}\begin{array}{c}\mathrm{ZnO} \text { NPs } \\
(\mathrm{mg} / \mathrm{L})\end{array} \\
8.56 \pm 0.41\end{array}$} & \multirow{2}{*}{$\begin{array}{c}\begin{array}{c}\zeta \text {-potential } \\
(\mathbf{m ~ V )}\end{array} \\
18.0 \pm 1.3\end{array}$} & \multirow{2}{*}{$\begin{array}{c}\begin{array}{c}\text { HDD } \\
\text { (nm) }\end{array} \\
458 \pm 56\end{array}$} & \multirow{2}{*}{$\frac{\mathbf{p H}}{7.06 \pm 0.02}$} \\
\hline & 0 & - & & & & & & \\
\hline \multirow{2}{*}{ Anionic } & 0.030 & \multirow{2}{*}{ SDS } & W1 & $1.524 \pm 0.04$ & $6.78 \pm 0.50$ & $-16.4 \pm 0.5$ & $280 \pm 35$ & $6.94 \pm 0.04$ \\
\hline & 0.050 & & W2 & $1.680 \pm 0.16$ & $6.12 \pm 0.31$ & $-28.3 \pm 0.8$ & $205 \pm 70$ & $6.76 \pm 0.17$ \\
\hline \multirow{2}{*}{ Nonionic } & 0.030 & \multirow{2}{*}{ NPEO } & W3 & 0.684 & 0.14 & 16.4 & $520 \pm 60$ & $7.02 \pm 0.01$ \\
\hline & 0.050 & & W4 & $0.921 \pm 0.33$ & $7.57 \pm 0.24$ & $12.1 \pm 0.4$ & $485 \pm 48$ & $6.85 \pm 0.13$ \\
\hline \multirow{2}{*}{ Anionic } & \multirow{2}{*}{0.050} & \multirow{2}{*}{ SDS } & (WW+SDS) & $3.587 \pm 0.02$ & $5.027 \pm 0.08$ & $-25.6 \pm 0.1$ & $190 \pm 35$ & $7.87 \pm 0.21$ \\
\hline & & & (TW+SDS) & $2.423 \pm 0.01$ & $7.41 \pm 0.10$ & $-14.0 \pm 0.3$ & $235 \pm 62$ & $6.95 \pm 0.34$ \\
\hline \multirow{2}{*}{ Nonionic } & \multirow{2}{*}{0.050} & \multirow{2}{*}{ NPEO } & $(\mathrm{WW}+\mathrm{NPEO})$ & $2.719 \pm 0.02$ & $6.09 \pm 0.23$ & $-17.8 \pm 0.5$ & $265 \pm 79$ & $7.56 \pm 0.15$ \\
\hline & & & (TW+NPEO) & $0.769 \pm 0.01$ & $8.26 \pm 0.08$ & $8.6 \pm 0.2$ & $584 \pm 98$ & $7.02 \pm 0.01$ \\
\hline
\end{tabular}

The $\mathrm{pH}$ of water samples was measured by (HACH-HQ40d portable multi-parameter meter, MA, USA). The TOC in water samples were analyzed using TOC analyzer (TOC-5000A, Shimadzu Corporation, Japan). Moreover, the concentrations of $\mathrm{F}^{-}, \mathrm{SO}_{4}{ }^{2-}, \mathrm{Cl}^{-}, \mathrm{HCO}_{3}-, \mathrm{K}^{+}, \mathrm{Ca}^{2+}, \mathrm{Na}^{+}$, and $\mathrm{Mg}^{2+}$ ions in the natural waters were measured with ion chromatography (861-Advanced Compact IC, Switzerland) using standard methods [21]. All of the collected water samples were filtered through $0.45 \mu$ glass fiber membrane and stored in $5 \mathrm{~L}$ amber reagent bottle before being used for the experiment.

\subsection{Laboratory Batch Experiments}

\subsubsection{Adsorption Study and Isotherm Modelling}

In order to fully understand the adsorption behaviors of the different surfactants on ZnO NPs surface, batch adsorption kinetics of SDS and NPEO (10 mg/L) on ZnO NPs (30 mg/L) at various $\mathrm{pH}$ ranges were determined. The $\mathrm{pHs}$ of the solutions were adjusted to 5.0, 7.0, and 9.0 with $\mathrm{NaOH}$ $(0.1 \mathrm{M})$ and $\mathrm{HCl}$. Subsequently, the suspensions vials were shaken at $150 \mathrm{rpm}$ in a shaker $(\mathrm{SK}, 300$ companions, Korea) and were sampled at consistent intervals of time from 0.5 to $72 \mathrm{~h}$. An aliquot of each mixture was taken and centrifuged for $30 \mathrm{~min}$ at 10,000 rpm using (Hettich Centrifuge Universal 320R) in order to measure the residual surfactant concentration using TOC analysis. The kinetics data of each surfactant at different $\mathrm{pH}$ onto $\mathrm{ZnO}$ surface was fitted by pseudo-first order (PFO), as well as pseudo-second-order (PSO), models Equations (1) and (2), respectively.

$$
\begin{gathered}
\log \left(q_{e}-q_{t}\right)=\log q_{e}-\frac{k_{1} t}{2.303} \\
\frac{t}{q_{t}}=\frac{1}{k_{2} q_{e}^{2}}+\frac{t}{q_{e}}
\end{gathered}
$$

where $q e$ and $q t$ are the adsorbed amounts of SDS and NPEO at equilibrium or any time $(\mathrm{mg} / \mathrm{g})$, respectively; $k_{1}(1 / \mathrm{h})$ and $k_{2}(\mathrm{~g} / \mathrm{mg} / \mathrm{h})$ represent the PFO and PSO rate constants, respectively.

Furthermore, stock solutions of both surfactants were diluted into vials in order to form $50 \mathrm{~mL}$ adsorption experiment suspension. The concentrations in the vials ranged between 0 to $50 \mathrm{mg} / \mathrm{L}$, and the $\mathrm{pHs}$ of all experimental solutions were adjusted to 5.0, 7.0, and 9.0. Afterwards, suspensions 
were shaken at $150 \mathrm{rpm}$ for $24 \mathrm{~h}$, so as to equilibrate the suspension, then centrifuged at 10,000 rpm for $30 \mathrm{~min}$. Moreover, in order to explore the adsorption mechanism and bond analysis onto NPs surface at different $\mathrm{pH}$ values, the Fourier transform infrared spectroscopy (JASCO, FT-IR-4700, USA) of ZnO NP surfactants complexes was conducted. The experimental data was further fitted with nonlinear forms of Langmuir and Freundlich isotherm models using Equations (3) and (4), respectively.

$$
\begin{gathered}
q_{e}=\frac{q_{m} K_{L} C_{e}}{1+K_{L} C_{e}} \\
q_{e}=K_{F} C_{e}^{\frac{1}{n}}
\end{gathered}
$$

where $q_{e}(\mathrm{mg} / \mathrm{g})$ is the adsorbed amount of SDS and NPEO on the $\mathrm{ZnO}$ surface; $C_{e}(\mathrm{mg} / \mathrm{L})$ is the equilibrium concentration of SDS and NPEO in suspension; $q_{m}$ and $K_{L}(\mathrm{~L} / \mathrm{mg})$ shows a maximum saturated adsorption amount and Langmuir constant relates to binding strength; and, $n$ and $K_{F}(\mathrm{~L} / \mathrm{mg})$ in the Freundlich equation relates to the intensity of heterogeneity and adsorption capacity, respectively.

\subsubsection{Sedimentation and Dissolution Kinetics in Different Waters}

The aggregation and sedimentation experiment of ZnO NPs was carried out in synthetic and environmental waters. The ZnO NPs stock suspension was spiked in water samples in the glass vials, so as to accomplish the desired concentrations, and was then immediately sonicated. The vials containing the mixtures were placed on a shaker and shaken at $150 \mathrm{rpm}$ for $24 \mathrm{~h}$ to simulate the circulation conditions within natural waters. After 24-h of equilibration, the $\zeta$-potential and intensity weighted average hydrodynamic diameter (HDD) of each suspension were measured with a dynamic light scattering (DLS) (Zeta-sizer NanoZS, Malvern, Worcestershire, UK) analyzer. Subsequently, the vials were left undisturbed, and the sedimentation rate of the NPs was measured with varying times through a turbidimeter (Hach Benchtop $2100 \mathrm{~N}$, Loveland, CO, USA). Since turbidity increases with NPs concentration, the sedimentation rate $\delta\left(C / C_{0}\right) / \delta$ t can be related to the normalized NPs turbidity $C / C_{0}$, where $C$ and $C_{0}$ are the turbidity at times $t$ and 0 , respectively. The sedimentation rate can be estimated from the initial 10\% decrease in normalized turbidity, which tends to occur within the first $2 \mathrm{~h}$ for fast sedimentation and within $24 \mathrm{~h}$ for slow sedimentation. For the dissolution experiment, the stock solution of $\mathrm{ZnO} N$ Ps was diluted into the $10 \mathrm{mg} / \mathrm{L}$ and dispersed through the ultrasonication. The $\mathrm{ZnO}$ NPs suspension was added in the equal volume of pure water as a control, tap water, and wastewaters suspension (Table 3). The initial concentration of $\mathrm{Zn}^{2+}$ ions in each water sample was recorded after the start of the experiments and left unattended for 10 days, as shown in Table 2. Subsequently, at different time intervals, an aliquot of $2 \mathrm{~mL}$ from each mixture was obtained and centrifuged at 10,000 rpm for $30 \mathrm{~min}$ prior to the $\mathrm{Zn}^{2+}$ ions concentration analysis.

\subsubsection{Coagulation-Flocculation Experiments}

Prior to the coagulation-flocculation experiment, the ZnO NP suspension that was prepared in $1 \mathrm{mM} \mathrm{NaHCO}_{3}$ solution was sonicated, as described previously in Section 2.2, and transferred into $250 \mathrm{~mL}$ beakers. The coagulant was dosed and $\mathrm{pH}$ was adjusted to 7.0 using $0.1 \mathrm{M} \mathrm{HCl}$ or $\mathrm{NaOH}$ solution. The coagulation experiments were performed using a jar tester (SJ10, Young Hana, Korea). The coagulation was carried out in three steps, as described in our earlier study [9], and precisely described as: (1) rapid mixing at $200 \mathrm{rpm}$ for $2 \mathrm{~min}$ to initialize the coagulation, (2) slow mixing at $40 \mathrm{rpm}$ for $20 \mathrm{~min}$ to increase flocculation, (3) and sedimentation for $30 \mathrm{~min}$. After sedimentation, $100 \mathrm{~mL}$ aliquot was collected from $2 \mathrm{~cm}$ below the surface for the analysis of various water quality parameters. The effect of FC dosage between 0 and $10 \mathrm{mg} / \mathrm{L}$ was studied on synthetic and natural waters samples, where 0 shows the control experiment (no coagulant) for each water sample. Each 
experiment was performed in triplicate and relative standard deviations (RSD) were reported, while the removal efficiency (\%) was calculated using Equation (5).

$$
\text { Removal efficiency }(\%)=\frac{C_{\mathrm{o}}-C_{\mathrm{f}}}{C_{\mathrm{o}}} \times 100
$$

where $C_{\mathrm{o}}(\mathrm{mg} / \mathrm{L})$ is the initial and $C_{\mathrm{f}}(\mathrm{mg} / \mathrm{L})$ is the final concentration of $\mathrm{ZnO} \mathrm{NPs}, \mathrm{Zn}^{2+}, \mathrm{SDS}$, and NPEO, respectively.

\subsection{Characterization and Measurement of $\mathrm{ZnO} N P$ s Suspension}

Following the coagulation experiment, $100 \mathrm{~mL}$ sample was immediately collected and centrifuged at 10,000 rpm for $30 \mathrm{~min}$ in order to analyze the $\mathrm{Zn}^{2+}$ and $\mathrm{ZnO}$ NPs in the solution. The residual concentration of metals in the supernatant was measured by Inductively Coupled Plasma Optical Emission Spectroscopy (ICP-OES, Agilent Technologies). The analysis of SDS and NPEO surfactant were quantified using liquid chromatography and then a mass spectrometer (MS 4500 Qtrap, AB SCIEX, USA). The optical properties of ZnO NPs were determined through absorption spectra using a UV Vis spectrophotometer (Optizen-2120, Mecasys, Korea) at $25 \pm 1{ }^{\circ} \mathrm{C}$ in a $10 \mathrm{~mm}$ quartz cuvette from the 250-800 $\mathrm{nm}$ wavelength range. The structural characterization of the $\mathrm{ZnO}$ powder, such as XRD, XPS, and Brunauer Emmett Teller (BET) specific surface area were investigated by Rigaku D max C III, X-ray diffractometry (Rigaku Corporation, Japan), and X-ray photoelectron spectroscopy (XPS) using (XSAM HS, KRATOS) and (ASAP 2020, Micromeritics, USA). Furthermore, Raman spectroscopy was acquired with a high-resolution confocal Lab Ram HR Evolution Horiba Jobin Yvon microscope.

\section{Results and Discussions}

\subsection{NPs Characterization and Properties}

The morphology and surface properties of pristine $\mathrm{ZnO} N \mathrm{Ns}$ were investigated through various characterization techniques. The UV - Vis spectra of ZnO NPs (Figure 1A) indicated that the strong absorption peak at $370 \mathrm{~nm}$, which should be derived from the $\pi-\pi^{*}$ transition of the $\mathrm{Zn}$ moiety [9]. The XPS spectra of ZnO NPs showed the $\mathrm{Zn} 2 \mathrm{p}_{1 / 2}$ and $2 \mathrm{p}_{3 / 2}$ binding energy peaks at 1042 and $1021 \mathrm{eV}$, respectively (Figure 1B). The $\mathrm{O} 1 \mathrm{~s}$ spectrum that is shown in the inset of (Figure 1B) also indicates that the binding energy of $\mathrm{O} 1 \mathrm{~s}$ is resolved into two major peaks, i.e., $530 \mathrm{eV}$ ascribed to surrounding $\mathrm{Zn}$ atoms and the peak at $531.2 \mathrm{eV}$ is attributed to the formation of $(\mathrm{Zn}-\mathrm{OH})$ with chemisorbed oxygen species [22]. The XRD pattern in (Figure 1C) shows the peaks at diffraction angles, i.e., $31.76^{\circ}, 34.37^{\circ}$, $36.24^{\circ}, 47.54^{\circ}, 56.58^{\circ}, 62.85^{\circ}$, and $67.97^{\circ}$, corresponding to the planes $\left(\begin{array}{llll}1 & 0 & 0\end{array}\right),\left(\begin{array}{lll}0 & 0 & 2\end{array}\right),\left(\begin{array}{lll}1 & 0 & 1\end{array}\right),\left(\begin{array}{lll}1 & 0 & 2\end{array}\right)$, $\left(\begin{array}{lll}1 & 1 & 0\end{array}\right),\left(\begin{array}{lll}1 & 0 & 3\end{array}\right)$, and $\left(\begin{array}{lll}1 & 1 & 2\end{array}\right)$, respectively. Therefore, it is indexed to a wurtzite hexagonal $\mathrm{ZnO}$ and a highly crystalline structure. The FT-IR spectra further revealed various chemically reactive functional groups and a capping agent on the outermost surface of ZnO NPs, as shown in (Figure 1D). The Raman spectra and specific surface area of ZnO NPs, as well as FT-IR analysis of both surfactants, were also conducted, as shown in Figure S1A-C. 

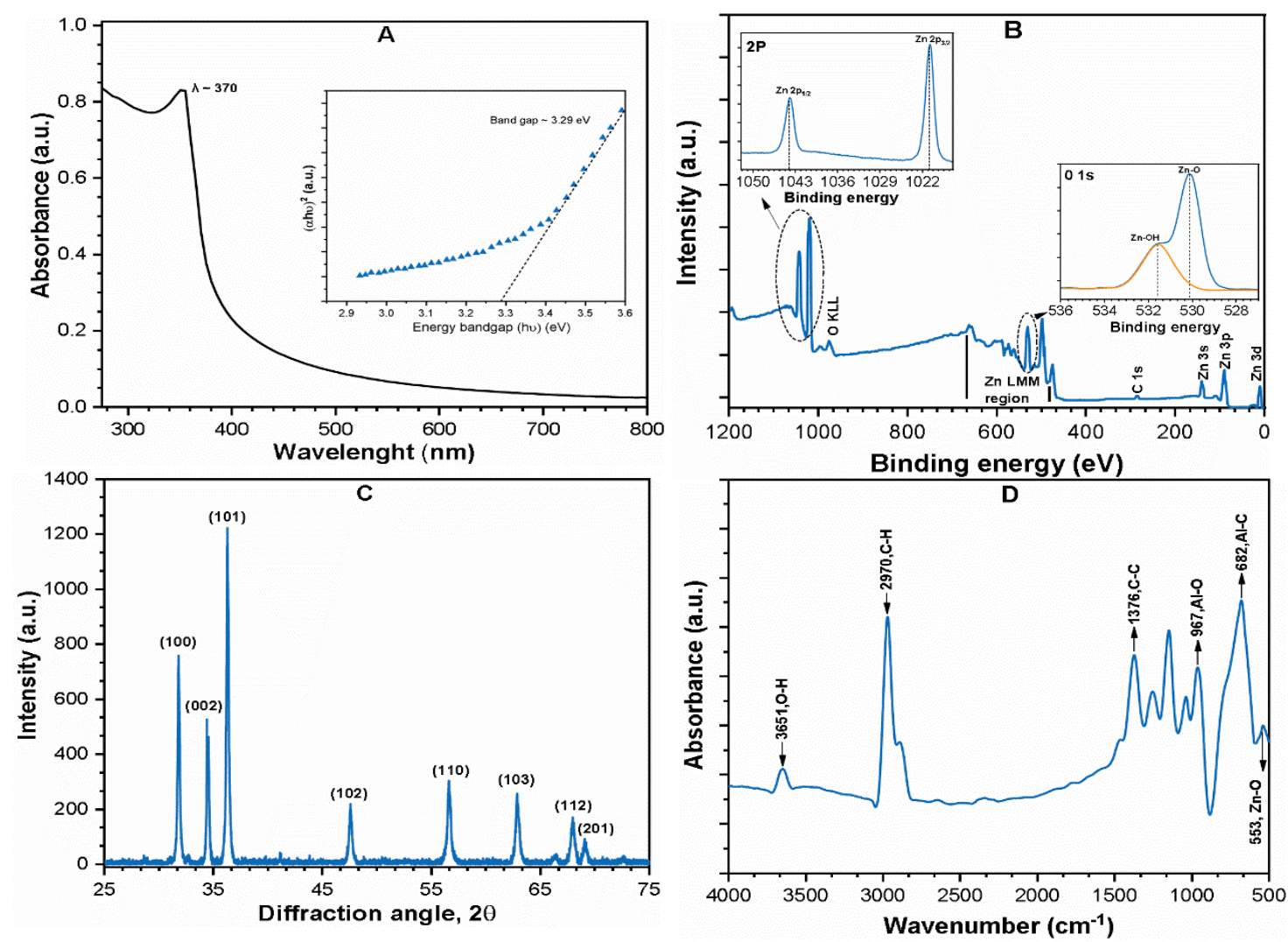

Figure 1. (A) UV-Vis spectra of ZnO NPs (10 mg/L) in ultra-pure water by full-wave scanning at pH 7; (B) High-resolution X-ray photoelectron spectroscopy (XPS) survey scan of ZnO; (C) XRD pattern of commercial ZnO NPs powder; and, (D) FT-IR spectra of ZnO. The inset in (Figure 1A,B) shows the band gap, $2 \mathrm{p}$ peak, and $\mathrm{O} 1 \mathrm{~s}$ peak, respectively.

\subsection{Effects of $\mathrm{pH}$ and Surfactants on $\zeta$-potential and HDD of ZnO NPs}

The influences of surfactants type and concentration on $\zeta$-potential and HDD of ZnO NPs suspension were determined at various pHs 5.0, 7.0, and 9.0 (Figure 2A,B). As shown in Figure 2A, SDS presented greater ability for strengthening the surface charge and promote the stability of $\mathrm{ZnO}$ suspension than NPEO in all $\mathrm{pH}$ ranges. For instance, as the SDS concentration increased from 0 to $0.05 \%$, the absolute value of $\zeta$-potential at $\mathrm{pH} 5.0,7.0$, and 9.0 significantly decreased from 12.32 to $-10.51,14.05$ to -21.14 , and 5.32 to $-35.96 \pm 2.39 \mathrm{mV}$, respectively. The NPEO exhibited no interference effect on $\zeta$-potential, even at higher concentrations in solution (Figure 2A), which was in accordance with the earlier study by Shimada et al. [19]. The low concentration of $0.015 \%$ of SDS at pH 5.0 and 7.0 sharply increases the HDD of ZnO NPs, with a maximum value of $2354.1 \pm$ 150.3 and $1822.6 \pm 153.8 \mathrm{~nm}$, respectively (Figure 2B), which corresponds to the neutralization of the $\mathrm{ZnO}$ NPs surface charge [23]. It has been proposed that at the appropriate concentration, the SDS efficiently compresses the double layer (DL) of NPs, which later decreases the electrostatic repulsive force [17]. However, the HDD of ZnO NPs rapidly declined and became much smaller upon an increase of SDS concentration above $0.02 \%$ (Figure $2 \mathrm{~B}$ ). A probable explanation might be that, when the $\zeta$-potential value is higher than \pm 15 to $\pm 20 \mathrm{mV}$, NPs tend to repel each other and remain stable in the suspension [24]. The impact of SDS on ZnO NPs suspension was intense at $\mathrm{pH} 7.0$ and 9.0, which was consistent with the findings of previous studies $[25,26]$ that positive charges on the surface of NPs provide favorable attachment sites for surfactant molecules. In addition, with the further increase of SDS concentration up to $0.05 \%$, the ZnO NPs HDD $(280.2 \pm 35.1 \mathrm{~nm})$ significantly reduces and becomes stable. This reversed the $\zeta$-potential from positive to negative and caused a significant increase in the 
absolute surface charge of ZnO NPs (Figure 2A). This might be due to the electro steric stabilization of ZnO NPs and shielding of SDS molecules by forming outer-sphere surface complexation [27].
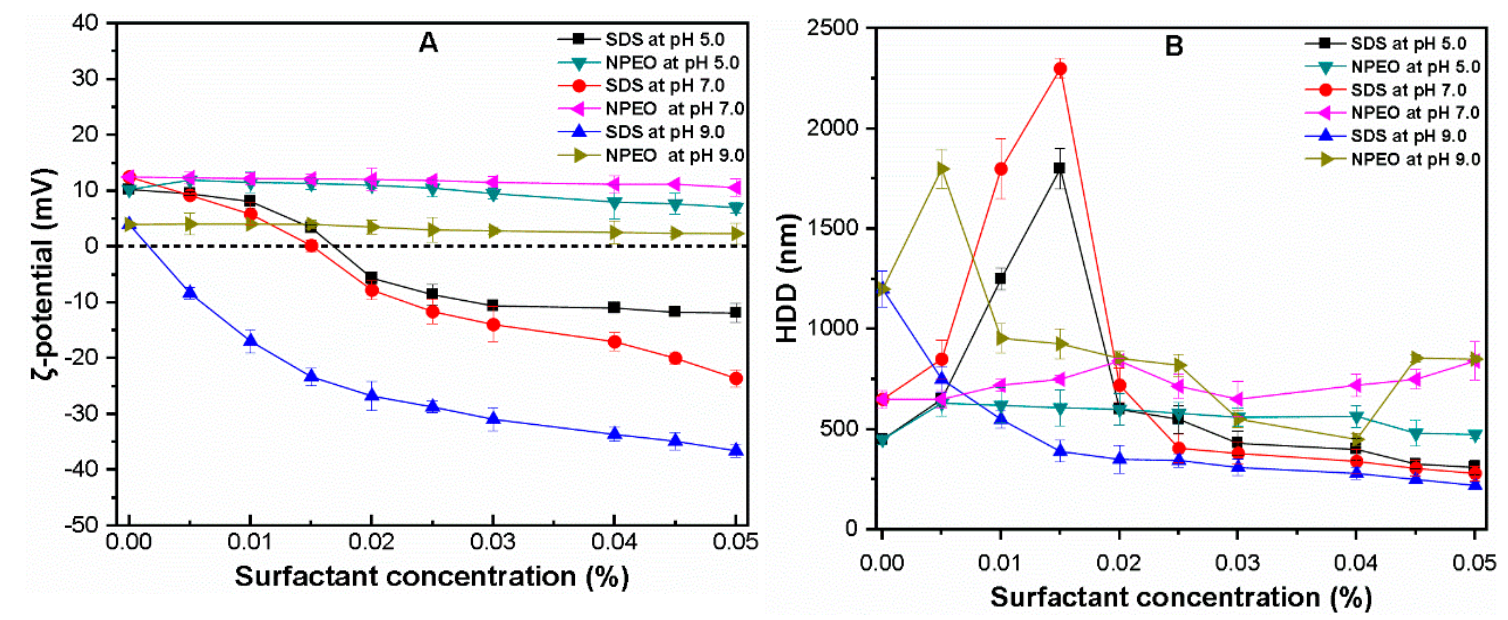

Figure 2. At various $\mathrm{pH}$ and concentration of surfactant showing (A) ל-potential; and, (B) hydrodynamic diameter (HDD) of ZnO NPs.

By contrast, the presence of NPEO surfactant reduced the HDD of the ZnO NPs aggregate without exerting any noticeable impact on the $\zeta$-potential throughout the $\mathrm{pH}$ range. Since non-ionic surfactants are non-charged and their hydrophilic part usually ester, phenol is non-dissociable, while the hydrophilic part contains the alkyl or alkylbenzene group $[17,19]$. Thus, due to the adsorption of non-ionic surfactant onto $\mathrm{ZnO}$ NPs through the process that reduced the agglomeration of the particle due to steric inhibition effect of surfactants macro-molecules. NPEO surfactant contains multiple phenol ring structures. As the NPEO concentration reached $0.05 \%$, the $\mathrm{ZnO}$ aggregate size reduced to $536.5 \pm 47.2,790 \pm 35.64$, and $800 \pm 50.84 \mathrm{~nm}$ at pH 5.0, 7.0, and 9.0, respectively. These results indicated that high concentrations of both surfactants significantly enhanced the stability of $\mathrm{ZnO}$ NPs. Moreover, the variations in charge reversal and HDD might be related to their specific adsorption mechanisms onto ZnO NPs. Thus, adsorption kinetics and isotherms modeling studies were conducted.

\subsection{Surfactants Adsorption onto NPs Surface}

Figure 3A,B show the adsorption kinetics of SDS and NPEO on the surface of ZnO NPs at various $\mathrm{pH}$. The adsorption rates of SDS and NPEO were rapid in the first $5 \mathrm{~h}$ in all studied $\mathrm{pH}$, and they reached 90.2 and $80.4 \%$ of their maximum adsorptions, respectively. However, it took an additional $17 \mathrm{~h}$ to reach $98 \%$ of their maximum adsorption capacity. This excellent sorption ability of surfactant might be attributable to the relatively high surface area of ZnO NPs. It has been reported previously $[28,29]$ that more interstices between NPs enhance the surfactants molecules binding to active sites of $\mathrm{ZnO}[28,29]$. It can also be observed that the adsorption efficiencies of SDS and NPEO on $\mathrm{ZnO}$ NPs were $\mathrm{pH}$ dependent with excellent sorption capacities at $\mathrm{pH} 9.0$ and 7.0. With increasing $\mathrm{pH}$, the surface charge of $\mathrm{ZnO}$ NPs gradually reversed from positive to negative, while the $\mathrm{Zn}-\mathrm{O}^{-}$on the surface at $\mathrm{pH} 9.0$ was gradually protonated to form $\mathrm{Zn}-\mathrm{OH}^{2+}[30,31]$. Moreover, the sulfate group that was present in SDS surfactant could bind to ZnO NPs to form outer-sphere complexes by replacing the previously adsorbed $\mathrm{OH}$ group [32]. Such phenomena could be weakened with decreasing $\mathrm{pH}$ due to the protonation of hydroxyl groups on NPs surface. 

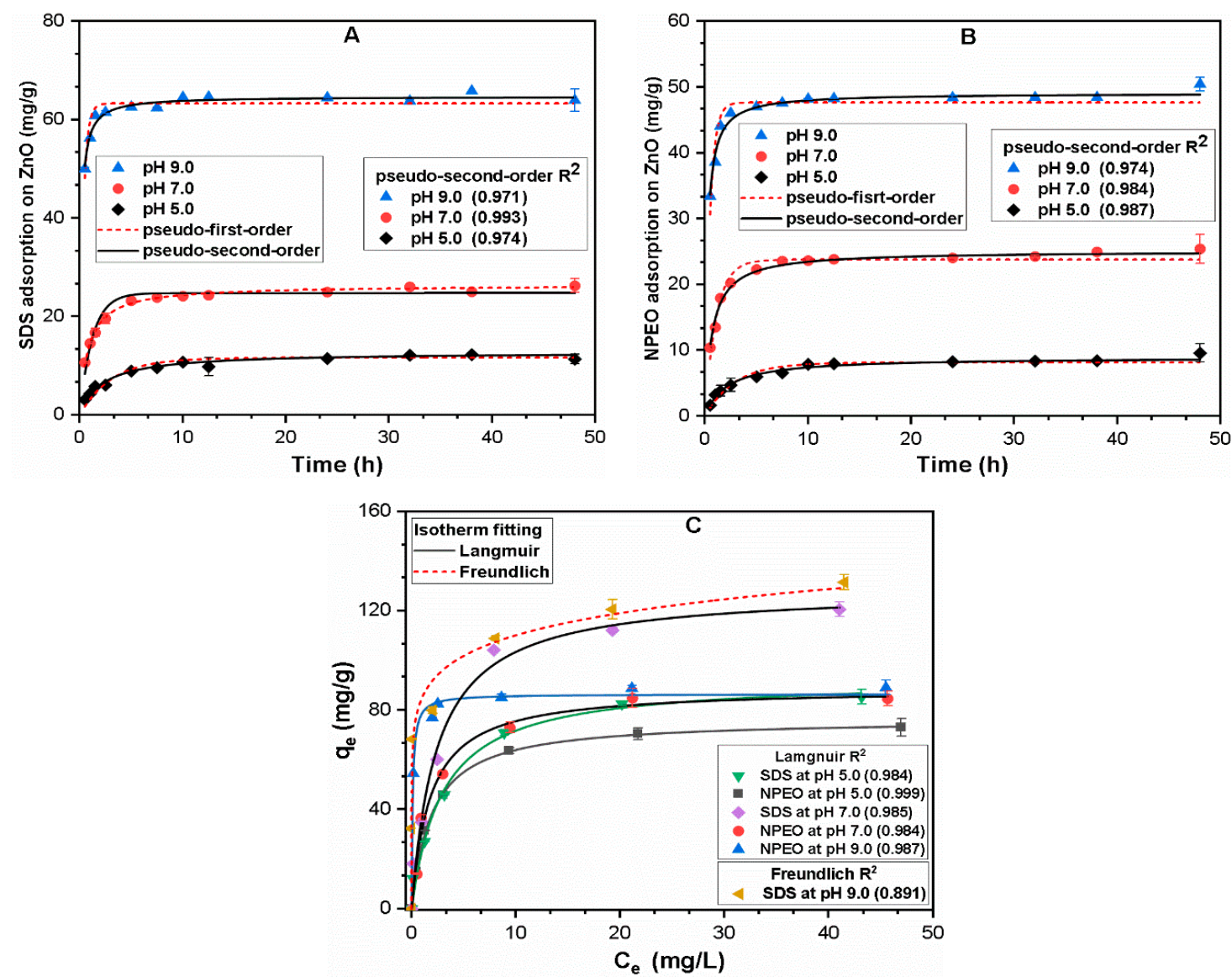

Figure 3. Adsorption kinetics study of (10 mg/L of each surfactant); (A) sodium dodecyl sulfate (SDS); (B) nonionic nonylphenol ethoxylate (NPEO); and, (C) isotherms modeling (0-50 mg/L of SDS and NPEO surfactants) at different $\mathrm{pH}$ onto $\mathrm{ZnO}$ NPs $(30 \mathrm{mg} / \mathrm{L})$.

Our results are consistent with previous studies $[14,17,19,24]$, which suggested that adsorption of SDS onto $\mathrm{TiO}_{2} \mathrm{NPs}$ was surface bond via H-Bond interaction between the sulfate head group and oxide surface. The adsorption of SDS was higher and faster than that of NPEO based on rate constants $(k)$ in all $\mathrm{pH}$ ranges (Table 4). The SDS is considered relatively more hydrophilic as compared with NPEO due to the higher contents of sulfate species $[14,33]$. Under the influence of electrostatic attractive and hydrophilic forces, SDS molecules could favorably be adsorbed onto the ZnO NPs surface. These results serve as a reconciliation with the previous observation [24] that anionic surfactants have a higher affinity to $\mathrm{TiO}_{2}$ NPs than nonionic surfactants due to their bilayer adsorption property on the colloid surface. It is noteworthy that the adsorptions of both surfactants were even observed at $\mathrm{pH}$ 5.0, but to a lesser extent, which might be ascribed to surfactant self-assembly interaction at the solid/aqueous interface. It was reported $[11,34]$ that the $\mathrm{H}^{+}$possessed a greater affinity for functional groups of $\mathrm{ZnO}$ NPs or negatively charged functional groups of surfactant molecules, both of which form a bridge with surfactant molecules, thereby bonding to ZnO NPs by competitive adsorption. Similar phenomena were also observed [34,35] for goethite NPs, where at lower $\mathrm{pH}$ organic pollutant adsorbed onto the surface by forming $\mathrm{H}-$ Bond between the $\mathrm{Fe}^{-} \mathrm{O}^{-}$and $\mathrm{O}-\mathrm{H}$ group of pollutant. The $\mathrm{PSO}$ model was fitted better due to its correlation coefficients being higher than PFO (Table 4). The results in Table 4 demonstrate that the attachment of surfactants onto ZnO NPs favors the chemisorption process that might be rate limiting in the sorption step of both surfactants. 
Table 4. The pseudo-first and second-order kinetics constants for adsorption of SDS and NPEO onto ZnO NPs.

\begin{tabular}{cccccccc}
\hline & \multicolumn{3}{c}{ Pseudo-First-Order } & \multicolumn{3}{c}{ Pseudo-Second-Order } \\
\hline Surfactant & $\mathbf{p H}$ & $\boldsymbol{q}_{\boldsymbol{e}}(\mathbf{m g} / \mathbf{g})$ & $\boldsymbol{k}_{\mathbf{1}} \mathbf{( 1 / \mathbf { h } )}$ & $\boldsymbol{R}^{\mathbf{2}}$ & $\boldsymbol{q}_{\boldsymbol{e}}$ & $\boldsymbol{k}_{\mathbf{2}}(\mathbf{g} / \mathbf{m g} / \mathbf{h})$ & $\boldsymbol{R}^{\mathbf{2}}$ \\
\hline \multirow{2}{*}{ SDS } & 5 & 11.58 & 0.745 & 0.914 & 12.76 & 0.0354 & 0.974 \\
& 7 & 24.77 & 1.881 & 0.928 & 26.33 & 0.0471 & 0.993 \\
& 9 & 63.27 & 6.582 & 0.858 & 64.72 & 0.1105 & 0.971 \\
\hline \multirow{2}{*}{ NPEO } & 5 & 8.134 & 0.806 & 0.950 & 8.956 & 0.0535 & 0.987 \\
& 7 & 23.76 & 2.099 & 0.966 & 25.09 & 0.0573 & 0.984 \\
& 9 & 47.66 & 4.740 & 0.896 & 49.09 & 0.0887 & 0.974 \\
\hline
\end{tabular}

In order to obtain a comprehensive understanding of adsorption behavior, the isotherm study was conducted under varying surfactant concentration $(0-50 \mathrm{mg} / \mathrm{L})$ with $\mathrm{ZnO} N$ Ps concentration $(30 \mathrm{mg} / \mathrm{L})$, as shown in Figure 2C. As expected, the NPEO surfactant shows less adsorption capacity than SDS. The isotherm of both surfactants reached a plateau at a concentration up to $25 \mathrm{mg} / \mathrm{L}$, indicating the nearly complete surface coverage (Figure 2C). The result of adsorption isotherms for binding of NPEO onto ZnO NPs at various $\mathrm{pH}$ was better fitted by the Langmuir model (Table 4). This observation indicated that electrostatic cross-linking forces might be responsible for the monolayer adsorption of NPEO onto $\mathrm{ZnO}$ due to the relatively high binding affinity of $\mathrm{Zn}^{2+}$ with a phenol group [24]. Similar results have been observed in previous studies [36,37], where the preferential adsorption of nonionic surfactant TX-100 was observed on the surfaces of $\mathrm{TiO}_{2}$. Similarly, the bridging effect on $\mathrm{TiO}_{2}$ may occur as nonionic surfactant micelles that would adsorb on surface, owing to the availability of the thermodynamically-favorable surface sites [37]. The fitted parameters of both surfactants sorption on ZnO NPs surface are shown in Table 5.

Table 5. Langmuir and Freundlich fitting parameters for SDS and NPEO adsorption onto ZnO NPs.

\begin{tabular}{cccccccc}
\hline & \multicolumn{3}{c}{ Langmuir Fitting } & \multicolumn{3}{c}{ Freundlich Fitting } \\
\hline Surfactant & $\mathbf{p H}$ & $\boldsymbol{K}_{\mathbf{L}}$ & $\boldsymbol{q}_{\max }$ & $\boldsymbol{R}^{\mathbf{2}}$ & $\boldsymbol{K}_{\mathbf{F}}$ & $\boldsymbol{n}$ & $\mathbf{R}^{\mathbf{2}}$ \\
\hline \multirow{3}{*}{ SDS } & $\mathbf{5 . 0}$ & $0.343 \pm 0.06$ & $92.67 \pm 4.15$ & 0.984 & $32.753 \pm 4.43$ & $3.569 \pm 0.57$ & 0.947 \\
& $\mathbf{7 . 0}$ & $0.413 \pm 0.07$ & $128.52 \pm 5.26$ & 0.985 & $46.528 \pm 6.98$ & $3.55 \pm 0.60$ & 0.930 \\
& $\mathbf{9 . 0}$ & $0.827 \pm 1.05$ & $130.11 \pm 26.58$ & 0.527 & $85.073 \pm 9.46$ & $8.89 \pm 3.10$ & 0.891 \\
\hline \multirow{2}{*}{ NPEO } & $\mathbf{5 . 0}$ & $0.516 \pm 0.01$ & $76.40 \pm 0.62$ & 0.999 & $31.206 \pm 4.39$ & $4.05 \pm 0.77$ & 0.921 \\
& $\mathbf{7 . 0}$ & $0.569 \pm 0.09$ & $88.91 \pm 3.28$ & 0.984 & $36.49 \pm 5.75$ & $4.00 \pm 0.85$ & 0.904 \\
& $\mathbf{9 . 0}$ & $9.731 \pm 2.02$ & $87.47 \pm 1.96$ & 0.987 & $70.52 \pm 2.46$ & $12.34 \pm 2.07$ & 0.981 \\
\hline
\end{tabular}

By contrast, the adsorptions of SDS were fitted better to Langmuir model at $\mathrm{pH} 5.0$ and 7.0, but the Freundlich model was more suitable at $\mathrm{pH}$ 9.0. This discrepancy suggests that the multilayer adsorption of SDS might be developed at $\mathrm{pH}$ 9.0, while the monolayer adsorption was formed under lower $\mathrm{pH}$ conditions. The possible mechanism for this would be that SDS presented high hydrophilicity at basic conditions, which mainly promoted multilayer adsorption of SDS on the NPs besides electrostatic interaction forces [27]. The adsorption trend of both surfactants suggests the uptake of surfactant-enhanced at higher $\mathrm{pH}$ values. This might be related to $\mathrm{H}^{+}$ion competition at lower $\mathrm{pH}$ value and the weakly acidic nature of the $\mathrm{ZnO}$ NPs active sites that favors the molecules bonding [38]. It can be concluded that ionic surfactant (SDS) adsorbed to ZnO NPs more effectively than nonionic surfactant (NPEO) due to the presence of higher levels of adsorptive interaction and electrostatic force. 


\section{Characteristics of ZnO-Surfactant Complexes}

The FT-IR spectra for $\mathrm{ZnO}$-surfactant complexes as a function of various $\mathrm{pH}$ were analyzed in order to illustrate the adsorption mechanisms, as shown in Figure 4. The appearance of some bands and shift in peaks of the $\mathrm{ZnO}$-surfactant complexes confirms that the surfactant made enough impact on the metal surface. The IR intensities are enhanced with increasing $\mathrm{pH}$ in both surfactants (Figure $3 \mathrm{~A}, \mathrm{~B}$ ). These results are consistent with $\mathrm{pH}$-dependent surface adsorption, with a predominance of outer-sphere complexation, as indicated by adsorption study (Figure 2). The peaks in the $3000-2800 \mathrm{~cm}^{-1}$ region in Figure 4A is ascribed to the asymmetric and symmetric stretching of $\mathrm{CH}_{3}$ and $\mathrm{CH}_{2}$ of the hydrocarbon tail $[39,40]$. This strong adsorption could be attributed to electrostatic interactions between the negatively charged sulfonate head and the positively charged hydroxyls groups in NPs [41]. The bands at 1461 and $1377 \mathrm{~cm}^{-1}$ correspond to the bending of $\mathrm{CH}_{2}$ and $\mathrm{CH}_{3}$ deformation, respectively [42]. The asymmetric doublet peak for $\mathrm{OSO}_{3}$ stretching in pristine SDS (Figure S1C) shifted down in frequency at $1198 \mathrm{~cm}^{-1}$ and it appeared in the spectrum of SDS adsorbed $\mathrm{ZnO}$ complexes [43]. This significant shift in wavenumber indicated that the primary adsorption mechanism might involve hydrophobic and electrostatic interactions.
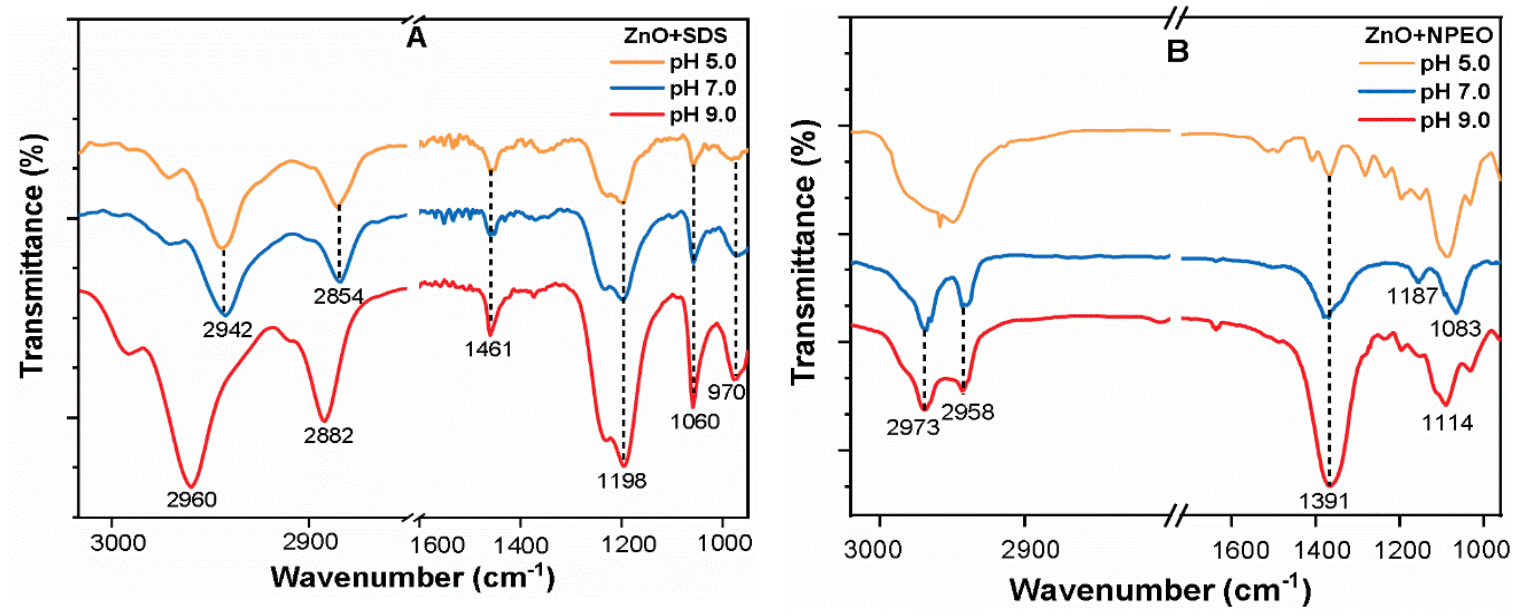

Figure 4. FT-IR spectra of $\mathrm{ZnO}$ NPs surfactant complexes at various $\mathrm{pH}$ and $(10 \mathrm{mg} / \mathrm{L})$ of each surfactant showing; (A) $\mathrm{ZnO}+\mathrm{SDS}$; (B) $\mathrm{ZnO}+\mathrm{NPEO}$.

Earlier reports [33] indicated that SDS adsorbed to the $\mathrm{Al}_{2} \mathrm{O}_{3}$ via $\mathrm{OSO}_{3}{ }^{-}$group and reduced remaining groups in the solution. A similar shift was previously reported [42], that, at appropriate SDS concentration, H-bond formation between one or two charged sulfonate oxygens and surface of $\mathrm{Zn}-\mathrm{OH}$ groups may occur. Therefore, during the adsorption of SDS onto ZnO NPs, the sulfate head group of SDS may directly interact with ZnO NPs surface. The possible adsorption mechanism at pH 5.0 may be that under these particular conditions $(\mathrm{pH}<\mathrm{pHiep}$ ), SDS micelles are weakly, but positively adsorbed to the $\mathrm{ZnO}$ NPs surface via counterion $\left(\mathrm{Na}^{+}\right)$bridging and attractive electrostatic forces $[44,45]$.

Figure 4B illustrates the NPEO spectra that were collected at different $\mathrm{pH}$ values. The two major visible spectral regions correspond to the hydrophobic tail $\left(2800-3000 \mathrm{~cm}^{-1}\right)$ and hydrophilic head $\left(1250-1050 \mathrm{~cm}^{-1}\right)$, respectively. A noticeable change in the ratio of the intensity of the hydrophilic tail relative to the phenol head was observed in all spectra. As indicated in Figure S2, the ZnO NPs were highly positively charged at pHs 5.0 and 7.0; thus, the adsorption may involve the formation of a surficial monolayer due to electrostatic attraction between the phenol head group with NPs surface [44]. Conversely, when $\mathrm{pH}$ is near the pHiep of $\mathrm{ZnO}$, the hydrophilic surface of NPs may still serve as a suitable substrate for adsorption of the surfactant tail, forming more complex cylindrical zinc micelles with the phenol head group toward the solution [45]. In addition, adsorption mechanisms between the NPEO molecules onto the ZnO NPs surface are thought to involve head group electrostatics and tail group lateral hydrophobic interactions. In conclusion, the specific adsorption characteristics of 
both surfactants affected the $\zeta$ - potential and the HDD of ZnO NPs. These finding might be instructive for assessing the colloidal stability of ZnO NPs in real wastewater.

\subsection{Sedimentation and Aggregation of $\mathrm{ZnO} N \mathrm{NPs}$ in Different Waters}

The sedimentation of $\mathrm{ZnO}$ aggregates in different kinds of waters over $24 \mathrm{~h}$ is presented in Figure 5. Notable aggregation and highest settling rate $(0.08,0.035$, and $0.32 / \mathrm{h})$ were observed for $24 \mathrm{~h}$ for $\mathrm{ZnO}$ NPs in control water, W3 and W4 (Figure $5 \mathrm{~A}, \mathrm{C}$ ), thus leaving only $20-50 \%$ of the suspended aggregate in the above solution. In the absence or little steric hindrance, NPs flocculates form more prominent aggregates with higher settling rate. However, the sedimentation is less distinct, and consequently the sediment rate was lowest $(0.01$ and $0.005 / \mathrm{h})$ in $\mathrm{W} 1, \mathrm{~W} 2$ waters containing the SDS surfactant (Figure 5A,C). It may be noted that over 80 and $95 \%$ of the $\mathrm{ZnO}$ NPs were still suspended after the experimental period. This could be attributed to the stronger steric hindrance generated by the surface attached anionic surfactant molecules that restricted the NPs aggregation [46]. Moreover, it might also be correlated well with the particle size of ZnO NPs in SDS containing waters, which was found to be at its lowest $(280 \pm 35$ and $205 \pm 70 \mathrm{~nm})$ in W1 and W2, respectively (Table 3). Many previous studies $[8,16,34]$ have indicated that smaller size NPs have a larger coefficient of diffusion in comparison to larger size NPs, which agglomerates rapidly in solution due to the effect of Brownian motion.
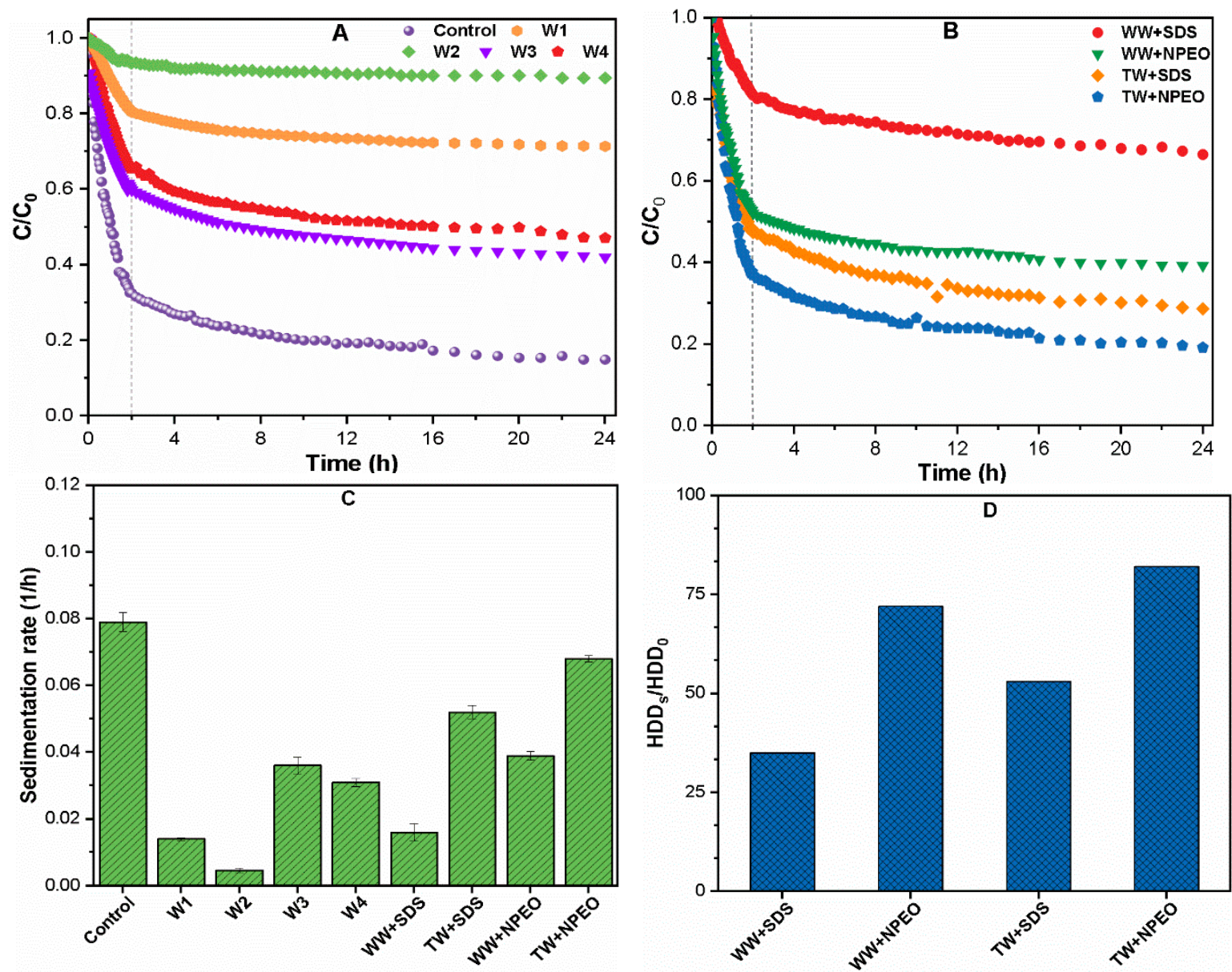

Figure 5. Aggregation kinetics (A) synthetic water; (B) environmental waters; (C) settling rate of $\mathrm{ZnO}$ NPs; and, (D) particle size ratio with and without surfactants.

As shown in Figure 5B, the ZnO NPs aggregates exhibited a pronounced difference with most stable in wastewater containing SDS and least suspended in remaining waters. The suspended $\mathrm{ZnO}$ 
NPs aggregates in TW+NPEO, and WW+NPEO waters were found to be 20.8 and $32.2 \%$, respectively. This discrepant behaviors of ZnO NPs in both environmental waters might be related to the IS. It has been reported [7] that an increase in IS will lead to effective compression of the electrical double layer (EDL), thereby reducing the interparticle repulsion forces and thus enhancing the rate of aggregation. In the presence of high electrolyte contents, the DOM may also increase the aggregation of ZnO NPs, through intermolecular bridging between DOM and ZnO NPs. Omar and Aziz $[47,48]$ reported that parameters, such as $\mathrm{pH}$ value, IS, and DOMs can affect the aggregation phenomena of ZnO NPs in the aqueous system. In addition, the presence of SDS in TW+SDS and WW+SDS waters increase the degree of suspension and around ( 40.10 and $70.96 \%)$ NPs were found to be suspended (Figure 5B). These results showed that $\mathrm{ZnO}$ dispersed in SDS has lesser agglomeration, indicating better dispersion due to the higher level of adsorption of SDS molecules onto the $\mathrm{ZnO}$ surface (Figure 2). The slightly higher aggregation in TW+SDS as compared to WW+SDS water may be related to the increasing interaction of SDS molecules with positively charged sites of electrolytes that can eliminate the energy barrier of NPs. Some studies have [49] reported that a high concentration of monovalent ions, such as $\mathrm{NaCl}$ $(10 \mathrm{mM})$, increased the sedimentation of hematite NPs and significantly reduced the critical micellar concentrations $(\mathrm{CMC})$ of anionic surfactants in solution. The reduced agglomeration is WW+SDS water might be related to the high TOC concentration $(15.68 \mathrm{mg} / \mathrm{L})$ in wastewater samples, thus suggesting the enhanced sorption competition between DOMs and ionic surfactants. Moreover, the presence of metal ions, such as antimony (Sb) and arsenic (As), may have some possible interference and contribution in the stability of NPs in such waters. However, further investigations are necessary to understand the complex aggregation phenomena in real wastewater containing heavy metals ions.

The size ratio of $\mathrm{ZnO}$ agglomerates after sedimentation are shown in Figure 5D, where $\mathrm{HDD}_{\mathrm{s}}$ and $\mathrm{HDD}_{0}$ are the sizes of $\mathrm{ZnO}$ agglomerates in the presence and absence of surfactants in the environmental waters, respectively. The presence of both surfactants reduced the aggregate size of the $\mathrm{ZnO}$ NPs in all studied waters. In general, the retarding effect of surfactants on the growth of aggregates was found to be most remarkable in waters containing SDS, in comparison to sample containing NPEO surfactant. The presence of SDS and NPEO in tap water reduced the agglomerates size by $51.67 \%$ and $25.91 \%$, respectively. Previous studies [50-55] have found that when the IS exceeds the critical coagulation concentration (CCC) value, the energy barriers are overcome, thereby increasing the agglomeration. The DOMs, such as humic acid, amino acid, and polyethylene glycol may generate the steric hindrance and electrostatic repulsion by adsorption onto NPs [31,51]. Moreover, the heavy metal ions that are present in wastewater might induce the cross-linking of NPs through the metal coordinating bonding, resulting in stable ZnO NPs suspension [8,34]. It has been proposed that the metal complexes be stabilized by a combination of ion-dipole, hydrophobic, and electrostatic interactions.

\section{Dissolution of ZnO NPs in Environmental Waters}

The time-dependent dissolution of ZnO NPs was measured for a 10-day period, as shown in Figure 6. The concentration of $\mathrm{Zn}^{2+}$ in pure water was $0.89 \mathrm{mg} / \mathrm{L}$ at the beginning, which increased to $4.82 \mathrm{mg} / \mathrm{L}$ at the last day (Figure 6). These results are consistent with the previous study report [38] that observed the enhanced released of $\mathrm{Zn}^{2+}$ up to $7.5-10 \mathrm{mg} / \mathrm{L}$ at $\mathrm{pH}$ 7. The solubility of $\mathrm{ZnO}$ NPs was found to be at its lowest in $\mathrm{pH}$ range 7-11, while it increased under highly acidic and alkaline conditions [9]. By contrast, the measured concentration of $\mathrm{Zn}^{+2}$ in WW+SDS ( $\left.3.587 \mathrm{mg} / \mathrm{L}\right)$ and $\mathrm{WW}+\mathrm{NPEO}(2.719 \mathrm{mg} / \mathrm{L})$ waters reduced to 1.40 and $2.01 \mathrm{mg} / \mathrm{L}$, respectively. The wastewater contains high concentrations of IS, TOC, and several anions, as well as metal ions. Therefore, a reduction in dissolution may account for the preferential formation of $\mathrm{Zn}$ complexes. Our observations are comparable with previous studies, which showed that the formation of hydrozincite $\left(\mathrm{Zn}_{5}\left(\mathrm{CO}_{3}\right)_{2}(\mathrm{OH})_{6}\right)$ in synthetic waters lead to a reduction of solubility of $\mathrm{ZnO}$ NPs [56,57]. In the heterogeneous aqueous environment, $\mathrm{ZnO}$ may form various $\mathrm{Zn}$ complexes, such as $\mathrm{Zn}$ phosphate, $\mathrm{Zn}$ iron hydroxides, and 
$\mathrm{Zn}$ sulfide [50-53]. These suspended complexes are less soluble as compared to pristine $\mathrm{ZnO}$. Hence, the solubility might reduce with the formation of $\mathrm{Zn}$ complexes.

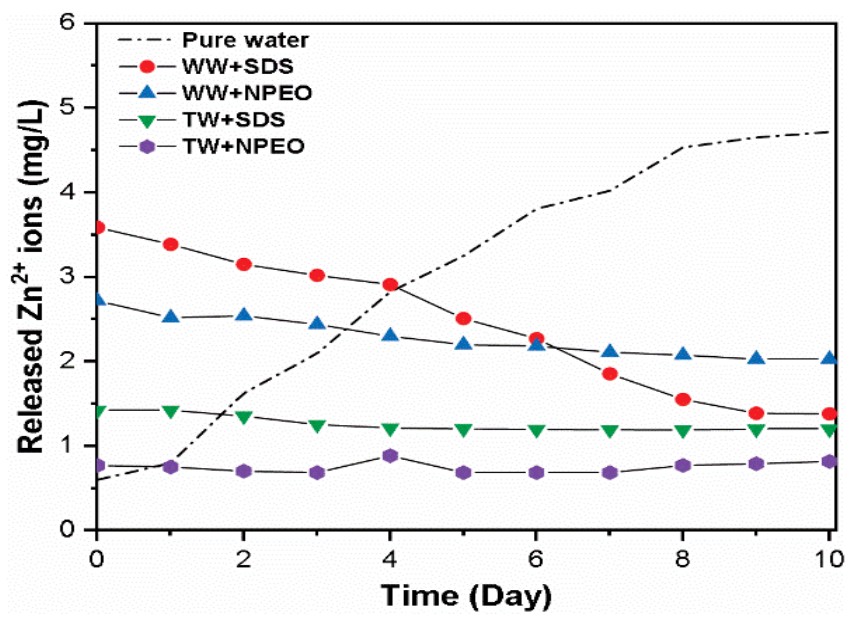

Figure 6. Time-dependent dissolution of ZnO NPs in surfactants containing environmental waters.

However, the $\mathrm{Zn}^{2+}$ concentration in TW+SDS $(2.423 \mathrm{mg} / \mathrm{L})$ and TW+NPEO $(0.769 \mathrm{mg} / \mathrm{L})$ waters remained stable within the whole experiment period. Our results are comparable with the dissolution patterns shown in previous studies $[19,23,31]$, which observed that dissolution reached the maximum value within the initial 2-4 days. In this study, the concentration of $\mathrm{Zn}^{2+}$ ions in other waters was lower than that in the pure water, which might be due to the inhibition effect from high electrolytes content and the low solubility effect of aqueous $\mathrm{pH}$. The phenomena behind the reduced solubility of $\mathrm{ZnO} N \mathrm{NP}$ in WW+SDS water in comparison to other three waters was complicated. However, as stated previously, a new series of experiments similar to current conditions are required to understand the reduced solubility in this complex's matrix, which was beyond the scope of this work. In general, when combining the high colloidal stability and enhanced solubility of ZnO NPs in waters containing SDS, it is worth noting that the stable colloid may decrease/influence the coagulation efficiency of NPs in the wastewater treatment process.

\subsection{Removal of $\mathrm{ZnO} N \mathrm{NP}_{\mathrm{s}}$ and $\mathrm{Zn}^{2+}$ from Synthetic Waters}

The removal of $\mathrm{ZnO}$ NPs and $\mathrm{Zn}^{2+}$ from synthetics and environmental waters after coagulation with various FC dosages are shown in Figure 7. In the absence of coagulant, only $30-40 \% \mathrm{ZnO}$ NPs removal was observed in synthetic waters (W1-W4), while in environmental waters, the ZnO NPs removal was found to be higher (50-65\%) in (TW+SDS, TW+NPEO) waters than in (WW+SDS, WW+NPEO) waters (20-25\%). The probable explanation for the higher removal rate in TW samples might be related to the presence of metal cations, i.e., $\mathrm{Mg}^{2+}$ and $\mathrm{Ca}^{2+}$, which could effectively compress the EDL and weaken the steric inhibition effect, thus enhancing NPs flocculation (ref). The results also indicated that the coagulation efficiencies of $\mathrm{Zn}^{2+}$ and surfactants were low, at (10-20\%) and $(<40 \%)$, respectively, in all the studied waters. 

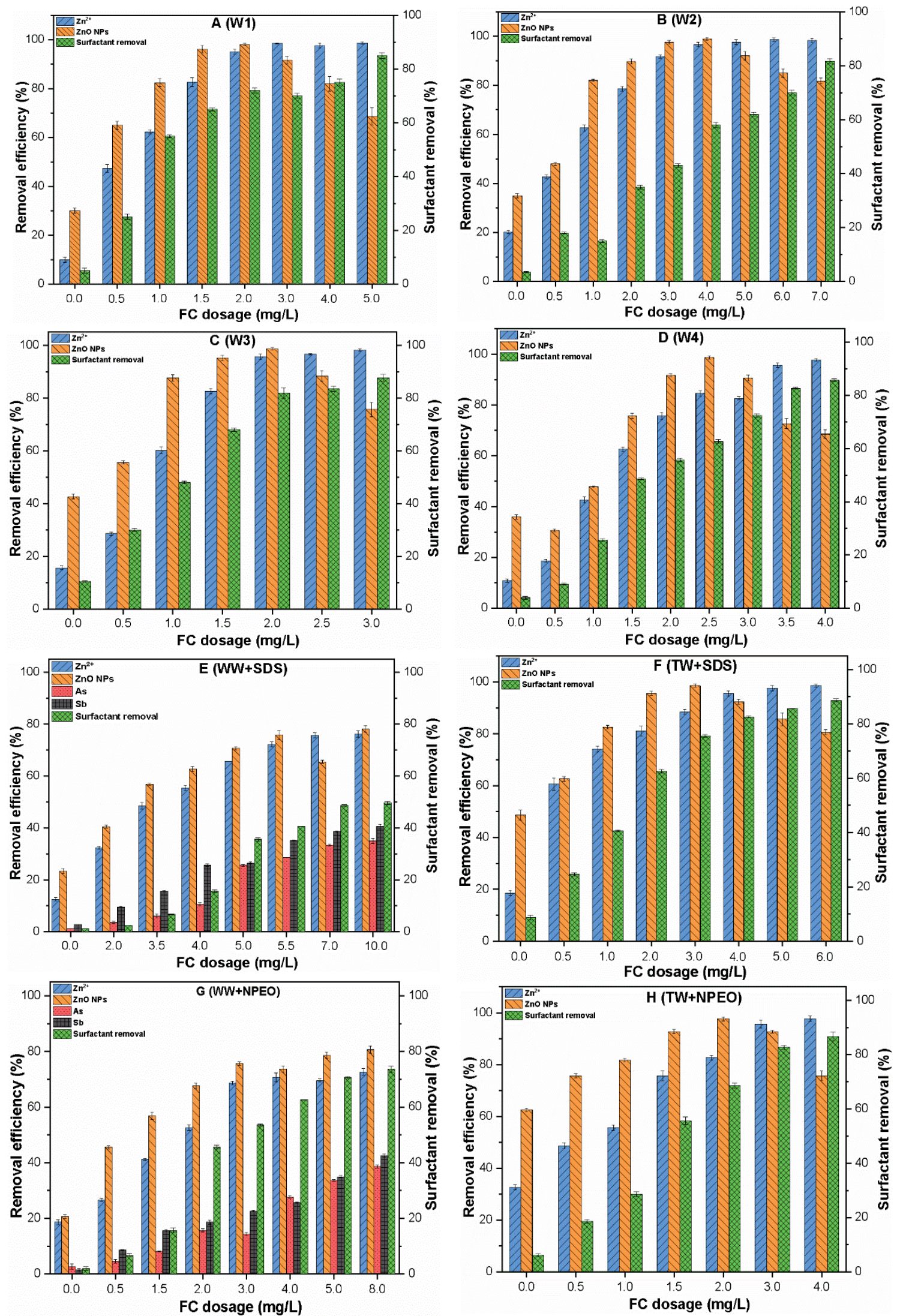

Figure 7. Removal of $\mathrm{ZnO} N P s, \mathrm{Zn}^{2+}$, surfactant, $\mathrm{As}$, and Sb from synthetic waters (A(W1)-D(W4)), and environmental waters $(\mathbf{E}-\mathbf{H})$, respectively, as a function of FC coagulant dosage. 
The removal efficiencies of $\mathrm{ZnO} N \mathrm{Ns}$ and $\mathrm{Zn}^{2+}$ enhanced with increasing FC dosage in all synthetic waters (Figure 7A-D). The presence of FC results in ampler NP flocs formation until reaching a plateau, i.e., where $\sim 98 \%$ of removal is achieved. The optimum FC dosage significantly varies among the surfactant type, such as the NPEO surfactant containing (W3, W4) waters that required lower optimum doses between 2.0 to $4.0 \mathrm{mg} / \mathrm{L}$ (Figure 7C,D). In addition, waters containing the SDS (W1, W2) required larger FC dosage between 3.0 to $5.0 \mathrm{mg} / \mathrm{L}$ to obtain maximum removal efficiency up to $95 \%$ of both contaminants. Since the ZnO NPs that were dispersed in the NPEO surfactants waters showed a larger size than waters containing SDS surfactants (Table 2, and Figure 7). The results suggested that NPs size plays an influential role in the estimation of optimum dosage (OD), as the smaller NPs have a larger diffusion coefficient, and thus required higher coagulant dosage then larger particles [9]. Many previous studies [54,55] have indicated that anionic surfactant forms stable aggregates, thus requiring more a coagulant dose to achieve a higher removal rate. The refractory nature of SDS might be responsible for the difference in $\mathrm{OD}$, because the presence of sulfonate groups in structure might decrease the electrostatic neutralization with the cationic Fe species of the coagulant [55]. In all studied waters, after OD, an excess of coagulant is counterproductive since it enhances the turbidity of suspension as $\zeta$-potential of ZnO NPs became more positive. Earlier reports $[9,18]$ indicated that the charge inversion and restabilization of coagulated colloids occur due to the excess adsorption of polyelectrolytes chains onto stable NPs in solution.

In all tested waters, the comparatively lower removal rate of $\mathrm{Zn}^{2+}$ ions was observed at a lower FC dosage, because of the lack of available FC sites in the aqueous phase. Interestingly, the higher removal efficiencies of $\mathrm{Zn}^{2+}$ up to $90-95 \%$ were observed at OD of FC in all synthetic waters (Figure 7A-D). It was assumed that heavy metals in cationic form might be associated with the precipitate matrix particle via the mechanism known as occlusion [56]. This result may explain the effect of electrolyte on $\mathrm{Zn}^{2+}$ removal from the heterogeneous aqueous environment and is consistent with previous literature [35,51]. The result confirms the finding of Sousa VS, et al. that, at lower coagulant dose, the interparticle bridging did not form due to the inadequate compression of EDL of stabilized NPs [57]. Further, increasing FC dosage induces the destabilization of colloid by neutralizing the electro steric forces through hydrolyzed $\mathrm{Fe}^{3+}$ species in suspension. The $\mathrm{ZnO}$ NPs that were spiked in SDS containing synthetic waters (W1, W2) have a negative surface charge $(-16.4 \pm 0.5$ and $-28.3 \pm 0.8)$ as compared to NPEO containing (W3, W4) waters with a slightly larger particle size (Table 2). In aquatic environments, the Fe hydrolysis product strongly adsorbs on the $\mathrm{ZnO}$ surface, thus reducing the $\zeta$-potential of suspension. Previous studies have reported [58] that NPs colloids might be practically neutralized when the $\zeta$-potential ranges between $\pm 20 \mathrm{mV}$. Our result implies that at OD, colloids are destabilized and bridging flocculation occurs due to an increase in attractive electrostatic charges among the NPs (Figure 7A-D). The surfactant may bind to ZnO NPs colloids through steric stabilization or electrostatic interaction and it enhanced the NPs mobility, as observed in aggregation and sedimentation experiment (Figure 5). The enmeshment effect of coagulant at the OD was stronger than the electro steric forces among the NPs and might play a dominant role in the removal of NPs from these waters.

\subsubsection{Removal of $\mathrm{ZnO} N \mathrm{NP}$ and $\mathrm{Zn}^{2+}$ from Environmental Waters}

Numerous jar tests experiments in environmental waters, such as tap water and wastewater, were conducted in order to establish a practical understanding of removal behavior of $\mathrm{ZnO} N P s$ and $\mathrm{Zn}^{2+}$ in the presence of both surfactants. In addition, the residual concentration of metal ions ( $\mathrm{Sb}, \mathrm{As}$ ) in wastewater was measured to evaluate the competitive inhibition effect of these ions on the removal process. The efficiency of $\mathrm{ZnO} N \mathrm{Ns}$ and $\mathrm{Zn}^{2+}$ removal was significantly influenced by the characteristics of treated waters, as shown in Figure 7E-H. The addition of lower dosage of FC in (TW+SDS and $\mathrm{TW}+\mathrm{NPEO}$ ) waters resulted in the enhanced removal rate of $\mathrm{ZnO} N \mathrm{Ns}$ and $\mathrm{Zn}^{2+}$, while no significant effect was observed in (WW+SDS and WW+NPEO) waters (Figure 7E-H). This is apparently due to the presence of high molecular weight (HMW) compounds in wastewater, thus hindering the electrostatic interactions between the ZnO NPs and FC coagulant [54]. The tap water containing both surfactants 
shows the similar removal phenomena of $\mathrm{ZnO} N P s$ and $\mathrm{Zn}^{2+}$ with complete removal at the optimum dosage of 3.0-4.0 mg/L (Figure 7F,H). An earlier study [57] reported that divalent metal cations might cause the ZnO NPs agglomeration in complex waters, owing to their specific adsorption behavior. By contrast, the complete removal of both pollutants from wastewater was not achieved, even at higher coagulant dosage (8.0-10.0 mg/L) (Figure 7E,G), and around (25\% $\mathrm{Zn}^{2+}$ and $\mathrm{ZnO} \mathrm{NPs}$ ) remains in the solution. The probable explanation might be that wastewater contains highly reactive species, which was elucidated through its high surface potential in aqueous media (Table 2). The simultaneous influence of other parameters such as the high metal concentration of As, Sb has an adverse effect on $\mathrm{ZnO} N P s$ and $\mathrm{Zn}^{2+}$ removal ratio. Thus, the removal rate decreased with the increase in competition adsorption between the species [56]. These results showed that higher concentration of other ions resulted in less neutralization, absorption, and interparticle bridging among NPs colloids and FC coagulant [43]. Overall, the removal efficiencies of metal ions increased with higher FC dosage as $\mathrm{Zn}^{2+}(70-75 \%), \mathrm{Sb}(30-40 \%)$, and As (30-35\%) were observed in WW+SDS and WW+NPEO waters due to the availability of more FC attachment sites. A previous study [59] reported that coagulation efficiencies significantly decreased in a complex matrix such as domestic and industrial wastewaters because of their variable origin. Regardless, the results indicate that the competitive inhibition effect of As, Sb species is due to strong adsorption potential on FC the surface [60,61]. Moreover, charge neutralization and adsorption to FC are the primary pollutant removal mechanisms that may act simultaneously during the water treatment by the coagulation-flocculation process.

\subsubsection{Removal of Surfactant from Synthetic and Environmental Waters}

The presence of different surfactant in real wastewater may affect the overall colloidal stability of $\mathrm{ZnO} N$ s. The reduction of surfactant content reached up to $80-85 \%$ in all synthetic and environmental waters, except for (WW+SDS), where less than 50\% removal was observed, even at higher FC dosages, while further increases in dosage did not improve the removal efficiency of the surfactants. The hydrophilic micropollutants, such as SDS with ( $\mathrm{pKa}=5.7)$, exist as negative ions at neutral $\mathrm{pH}$ [62]. Therefore, it can be effectively removed with a $\mathrm{Fe}^{3+}$ ion from synthetic waters by the coagulation process. The lower removal of surfactant from (WW+SDS) water might be related to the solubilization capacity of surfactants and NOM, which increase the dissolution effect in the solution. Similar results were obtained by Stackelberg et al., which shows the low removal $<40 \%$ of micropollutant ats the coagulation step in water treatment plant [55]. The presence of surfactants in these waters further stabilized the NPs-NOMs composite due to their ionization state and surface-active properties, and thus produced thermodynamically stabilized suspension. In addition, the extended H-Bonding might enhance the steric stabilization effect due to the change in the surfactant layer configuration [62]. It was assumed that the polarized groups of surfactant interacted predominantly with the hydroxyl group of FC via hydrophobic interactions, producing an increasingly hydrophilic surface [9]. The measured $\zeta$-potential during the coagulation further explained the removal phenomena, such as the higher removal, were obtained at the $\zeta$-potential around $\pm 10 \mathrm{mV}$, while the removal rate decreases at $\zeta$-potential $(> \pm 30 \mathrm{mV})$. It has been reported [57] that at $\zeta$-potential $(+3$ and $-10 \mathrm{mV})$, the removal of most stable colloids can be easily achieved. The results also suggest that the organic fractions mostly composed of the aromatic compound $\left(\mathrm{UV}_{254}\right)$ and dissolved organic carbon (DOC) were efficiently removed from wastewaters. These conclusions are consistent with previous studies $[9,14,51,58]$ that HMW aromatic compounds are removed more easily than other fractions. At OD, the high charge metal cations $\mathrm{Fe}^{3+}$ may bind to the surface of the micellar and creates a region of high cation concentration across the Stern and diffuse layer around the micelle. Shielding of surface charge leads to flocculation of the micelles, which form a large disordered structure, amorphous with fragments of the liquid crystal inlaid [54]. Moreover, organic pollutants may adsorb as complexes within the Stern-diffuse layer due to the high concentration of polyvalent cations. This process reduces the $\zeta$-potential of the residual suspension, thereby removing the pollutant through the adsorptive micellar flocculation (AMF) [59]. The conditions for the coagulation of the surfactant are similar to organic matter, thus 
understanding the AMF process is needed to help explain this sequestering behavior in wastewater and its applicability limits. It can be concluded that, in addition to the charge neutralization process, the AMF mechanism may also contribute to the removal of surfactants and organic matters from wastewater. Based on our finding, surfactant type, concentration, and other metal ions appear to be a crucial factor in influencing the treatability in environmental waters and it should be included in any mechanistic approach to water treatment.

\subsection{Study Significance and Limitation}

This study is the first-time approach to provide some insight into the aggregation, dissolution, and removal behavior of ZnO NPs in synthetic and real wastewater containing various surfactants, as well as heavy metal ions. Previous studies by $[10,14,17,40,41]$ have described the effect of surfactant on the individual parameters of ENPs. No study has yet been conducted that describes the influence of different surfactants on the removal of ZnO NPs from real industrial wastewater. The current study was conducted on four synthetic and two real waters with different characteristics and surfactant concentration. The results highlight that the sorption of anionic surfactant onto $\mathrm{ZnO} N P$ s restricted the aggregation through steric hindrance and enhanced the solubility. Thus, the transformation of ZnO NPs into heavy metal ions may alter their fate, bioavailability, and the potential effect on biota. However, the agglomeration of NPs decreases the rate of dissolution in environmental waters by reducing surface area for the sorption of surfactant molecules. The major limitation of this study is the unavailability of examined data of other wastewater quality parameters, such as $\mathrm{Cu}$ metal ions and organic fractions of compounds, which might play a critical role in influencing the removal efficiency of $\mathrm{Zn}^{2+}$ ions. Moreover, it should also be noted that a further investigation is needed to study the competitive effect of heavy metals on NPs removal. In this study, we only considered the higher concentration of ions, such as $\mathrm{As}$ and $\mathrm{Sb}$, with maximum possible discussion, providing insight into the overall effect of surfactant on coagulation behavior. Here, we demonstrated that the coagulation process could completely remove $\mathrm{ZnO} N P s, \mathrm{Zn}^{2+}$, and other micropollutants from synthetic waters; however, it shows a limited removal performance in real wastewater under the studied dosage. This study underscores the importance of understanding the effect of different surfactants on the transport and fate of $\mathrm{ZnO} N \mathrm{NP}$ in the wastewater environment.

\section{Conclusions}

In this study, we investigated the influence of ionic (SDS) and nonionic (NPEO) surfactants on ZnO NPs stability and removal behavior from synthetic and natural waters by the coagulation-flocculation process. The presence of SDS significantly decreased the $\zeta$-potential and aggregate size, thereby hindering the NPs aggregation rate. This study found that both surfactants could be adsorbed onto $\mathrm{ZnO}$ NPs surface with the strong sorption capacity of SDS as compared to NPEO. The FT-IR analysis of $\mathrm{ZnO}$-surfactants composite indicated the strong $\mathrm{pH}$-dependence with increasing IR intensities due to the formation of mono-bilayer patches onto the $\mathrm{ZnO}$ surface. The presence of both surfactants in environmental waters results in a distinct adverse effect on dissolution and aggregate size of ZnO NPs, while the effect of SDS was more pronounced than NPEO. The results showed that, at optimum FC dosage, the removal efficiencies of $\mathrm{ZnO} N P s, \mathrm{Zn}^{2+}$, and surfactant were more than 98,95 , and $85 \%$, respectively, in all synthetic waters. However, the presence of higher concentration of metals ions in wastewater significantly inhibited the coagulation efficiency of $\mathrm{Zn}^{2+}, \mathrm{ZnO}$, and surfactant up to 20, 25 , and $50 \%$, respectively. The mechanisms, such as charge neutralization and adsorptive micellar flocculation (AMF), might be involved in the removal of NPs composite pollutant by coagulation. The future research and endeavors shall focus on polymerized coagulants, such as polyaluminum chloride, polyferric chloride, and polyferric sulphate, which might enhance the coagulation efficiency of ZnO NPs under competitive conditions. 
Supplementary Materials: The following are available online at http:/ /www.mdpi.com/2071-1050/11/1/17/s1, Figure S1. (A) BET surface Area; (B) Raman spectra of ZnO powder; and (C) FT-IR spectra of SDS and NPEO

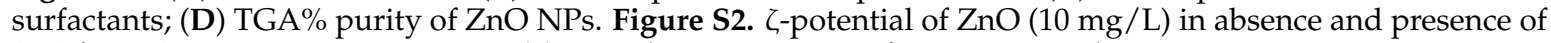
SDS/NPEO at various $\mathrm{pH}$ ranges. Table S1. The composition of environmental waters.

Author Contributions: R.K. and I.T.Y. designed the study; R.K., M.A.I., performed the experiment and analyzed the data; M.M.I., M.S.; D.R.P., K.H.L., S.S. and S.K. provided critical feedback and helped shape the research; R.K. wrote final version of the manuscript.

Acknowledgments: The BK21 plus program supported this research through the National Research Foundation of Korea (NRF) funded by the Ministry of Education of Korea (Grant No. 22A20152613545).

Conflicts of Interest: The authors declare no conflict of interest.

\section{References}

1. Wang, Z.L. Zinc oxide nanostructures: Growth, properties and applications. J. Phys. Condens. Matter 2004, 16. [CrossRef]

2. Gottschalk, F.; Nowack, B. The release of engineered nanomaterials to the environment. J. Environ. Monit. 2011, 13, 1145. [CrossRef]

3. Keller, A.A.; McFerran, S.; Lazareva, A.; Suh, S. Global life cycle releases of engineered nanomaterials. J. Nanopart. Res. 2013, 15. [CrossRef]

4. Adam, N.; Leroux, F.; Knapen, D.; Bals, S.; Blust, R. The uptake and elimination of $\mathrm{ZnO}$ and $\mathrm{CuO}$ nanoparticles in Daphnia magna under chronic exposure scenarios. Water Res. 2015, 68, 249-261. [CrossRef] [PubMed]

5. Dreher, K.L. Health and environmental impact of nanotechnology: Toxicological assessment of manufactured nanoparticles. Toxicol. Sci. 2004, 77, 3-5. [CrossRef] [PubMed]

6. Zhou, D.; Keller, A.A. Role of morphology in the aggregation kinetics of ZnO nanoparticles. Water Res. 2010, 44, 2948-2956. [CrossRef]

7. Peng, Y.-H.; Tso, C.; Tsai, Y.; Zhuang, C.; Shih, Y. The effect of electrolytes on the aggregation kinetics of three different ZnO nanoparticles in water. Sci. Total Environ. 2015, 530, 183-190. [CrossRef]

8. Khan, R.; Inam, M.; Zam, S.; Park, D.; Yeom, I. Assessment of Key Environmental Factors Influencing the Sedimentation and Aggregation Behavior of Zinc Oxide Nanoparticles in Aquatic Environment. Water 2018, 10, 660. [CrossRef]

9. Khan, R.; Inam, M.; Park, D.; Zam Zam, S.; Shin, S.; Khan, S.; Akram, M.; Yeom, I. Influence of Organic Ligands on the Colloidal Stability and Removal of ZnO Nanoparticles from Synthetic Waters by Coagulation. Processes 2018, 6, 170. [CrossRef]

10. Narkis, N.; Ben-David, B. Adsorption of non-ionic surfactants on activated carbon and mineral clay. Water Res. 1985, 19, 815-824. [CrossRef]

11. Bouchard, D.; Zhang, W.; Powell, T.; Rattanaudompol, U. Aggregation kinetics and transport of single-walled carbon nanotubes at low surfactant concentrations. Environ. Sci. Technol. 2012, 46, 4458-4465. [CrossRef] [PubMed]

12. Lewis, M.A. Chronic and sublethal toxicities of surfactants to aquatic animals: A review and risk assessment. Water Res. 1991, 25, 101-113. [CrossRef]

13. Godinez, I.G.; Darnault, C.J.G. Aggregation and transport of nano- $\mathrm{TiO}_{2}$ in saturated porous media: Effects of $\mathrm{pH}$, surfactants and flow velocity. Water Res. 2011, 45, 839-851. [CrossRef] [PubMed]

14. Li, X.; Yoneda, M.; Shimada, Y.; Matsui, Y. Effect of surfactants on the aggregation and stability of $\mathrm{TiO}_{2}$ nanomaterial in environmental aqueous matrices. Sci. Total Environ. 2017, 574, 176-182. [CrossRef] [PubMed]

15. Zhang, Y.; Chen, Y.; Westerhoff, P.; Crittenden, J. Impact of natural organic matter and divalent cations on the stability of aqueous nanoparticles. Water Res. 2009, 43, 4249-4257. [CrossRef] [PubMed]

16. Keller, A.A.; Wang, H.; Zhou, D.; Lenihan, H.S.; Cherr, G.; Cardinale, B.J.; Miller, R.; Zhaoxia, J.I. Stability and aggregation of metal oxide nanoparticles in natural aqueous matrices. Environ. Sci. Technol. 2010, 44, 1962-1967. [CrossRef]

17. Liu, L.; Gao, B.; Wu, L.; Sun, Y.; Zhou, Z. Effects of surfactant type and concentration on graphene retention and transport in saturated porous media. Chem. Eng. J. 2015, 262, 1187-1191. [CrossRef] 
18. Tkachenko, N.H.; Yaremko, Z.M.; Bellmann, C.; Soltys, M.M. The influence of ionic and nonionic surfactants on aggregative stability and electrical surface properties of aqueous suspensions of titanium dioxide. J. Colloid Interface Sci. 2006, 299, 686-695. [CrossRef]

19. Li, X.; Yoneda, M.; Shimada, Y.; Matsui, Y. Effect of surfactants on the aggregation and sedimentation of zinc oxide nanomaterial in natural water matrices. Sci. Total Environ. 2017, 581, 649-656. [CrossRef]

20. Sun, P.; Zhang, K.; Fang, J.; Lin, D.; Wang, M.; Han, J. Transport of $\mathrm{TiO}_{2}$ nanoparticles in soil in the presence of surfactants. Sci. Total Environ. 2015, 527, 420-428. [CrossRef]

21. Apha, A. WPCF, Standard Methods for the Examination of Water and Wastewater; American Public Health Association: Washington, DC, USA, 1995.

22. Wagner, C.D.; Gale, L.H.; Raymond, R.H. Two-dimensional chemical state plots: A standardized data set for use in identifying chemical states by x-ray photoelectron spectroscopy. Anal. Chem. 1979, 51, 466-482. [CrossRef]

23. Rupasinghe, R.A. Dissolution and Aggregation of Zinc Oxide Nanoparticles at Circumneutral pH: A Study of Size Effects in the Presence and Absence of Citric Acid. Master's Thesis, University of Iowa, Iowa City, IA, USA, 2011.

24. Chibowski, E.; Holysz, L.; Terpilowski, K.; Wiacek, A.E. Influence of ionic surfactants and lecithin on stability of titanium dioxide in aqueous electrolyte solution. Croat. Chem. Acta 2007, 80, 395-403.

25. Saleh, N.; Kim, H.-J.; Phenrat, T.; Matyjaszewski, K.; Tilton, R.D.; Lowry, G.V. Ionic strength and composition affect the mobility of surface-modified $\mathrm{Fe} 0$ nanoparticles in water-saturated sand columns. Environ. Sci. Technol. 2008, 42, 3349-3355. [CrossRef] [PubMed]

26. Nevskaia, D.M.; Guerrero-Ruız, A.; de D. López-González, J. Adsorption of polyoxyethylenic nonionic and anionic surfactants from aqueous solution: Effects induced by the addition of $\mathrm{NaCl}$ and $\mathrm{CaCl}_{2}$. J. Colloid Interface Sci. 1998, 205, 97-105. [CrossRef] [PubMed]

27. Shao, D.; Jiang, Z.; Wang, X. SDBS Modified XC-72 Carbon for the Removal of Pb (II) from Aqueous Solutions. Plasma Process. Polym. 2010, 7, 552-560. [CrossRef]

28. Ho, Y.-S. Review of second-order models for adsorption systems. J. Hazard. Mater. 2006, 136, 681-689. [CrossRef]

29. Qiu, H.; Lv, L.; Pan, B.; Zhang, Q.; Zhang, W.; Zhang, Q. Critical review in adsorption kinetic models. J. Zhejiang Univ. A 2009, 10, 716-724. [CrossRef]

30. Illés, E.; Tombácz, E. The effect of humic acid adsorption on $\mathrm{pH}$-dependent surface charging and aggregation of magnetite nanoparticles. J. Colloid Interface Sci. 2006, 295, 115-123. [CrossRef]

31. Hu, J.-D.; Zevi, Y.; Kou, X.-M.; Xiao, J.; Wang, X.-J.; Jin, Y. Effect of dissolved organic matter on the stability of magnetite nanoparticles under different $\mathrm{pH}$ and ionic strength conditions. Sci. Total Environ. 2010, 408, 3477-3489. [CrossRef]

32. Filius, J.D.; Meeussen, J.C.L.; Lumsdon, D.G.; Hiemstra, T.; van Riemsdijk, W.H. Modeling the binding of fulvic acid by goethite: The speciation of adsorbed FA molecules. Geochim. Cosmochim. Acta 2003, 67, 1463-1474. [CrossRef]

33. Piccolo, A.; Conte, P.; Spaccini, R.; Chiarella, M. Effects of some dicarboxylic acids on the association of dissolved humic substances. Biol. Fertil. Soils 2003, 37, 255-259.

34. Philippe, A.; Schaumann, G.E. Interactions of dissolved organic matter with natural and engineered inorganic colloids: A review. Environ. Sci. Technol. 2014, 48, 8946-8962. [CrossRef] [PubMed]

35. Filius, J.D.; Lumsdon, D.G.; Meeussen, J.C.L.; Hiemstra, T.; Van Riemsdijk, W.H. Adsorption of fulvic acid on goethite. Geochim. Cosmochim. Acta 2000, 64, 51-60. [CrossRef]

36. Romero-Cano, M.; Martín-Rodríguez, A.; de las Nieves, F. Electrokinetic behaviour of polymer colloids with adsorbed Triton X-100. Colloid Polym. Sci. 2002, 280, 526-532.

37. Sharma, K.P.; Aswal, V.K.; Kumaraswamy, G. Adsorption of nonionic surfactant on silica nanoparticles: Structure and resultant interparticle interactions. J. Phys. Chem. B 2010, 114, 10986-10994. [CrossRef] [PubMed]

38. Bian, S.W.; Mudunkotuwa, I.A.; Rupasinghe, T.; Grassian, V.H. Aggregation and dissolution of $4 \mathrm{~nm} \mathrm{ZnO}$ nanoparticles in aqueous environments: Influence of $\mathrm{pH}$, ionic strength, size, and adsorption of humic acid. Langmuir 2011, 27, 6059-6068. [CrossRef] [PubMed]

39. Bai, B.; Hankins, N.P.; Hey, M.J.; Kingman, S.W. In situ mechanistic study of SDS adsorption on hematite for optimized froth flotation. Ind. Eng. Chem. Res. 2004, 43, 5326-5338. [CrossRef] 
40. Dobson, K.D.; Roddick-Lanzilotta, A.D.; McQuillan, A.J. In situ infrared spectroscopic investigation of adsorption of sodium dodecylsulfate and of cetyltrimethylammonium bromide surfactants to $\mathrm{TiO}_{2}, \mathrm{ZrO}_{2}$, $\mathrm{Al}_{2} \mathrm{O}_{3}$, and $\mathrm{Ta}_{2} \mathrm{O}_{5}$ particle films from aqueous solutions. Vib. Spectrosc. 2000, 24, 287-295. [CrossRef]

41. Gao, X.; Chorover, J. Adsorption of sodium dodecyl sulfate (SDS) at $\mathrm{ZnSe}$ and $\alpha-\mathrm{Fe}_{2} \mathrm{O}_{3}$ surfaces: Combining infrared spectroscopy and batch uptake studies. J. Colloid Interface Sci. 2010, 348, 167-176. [CrossRef]

42. Hug, S.J. In situ fourier transform infrared measurements of sulfate adsorption on hematite in aqueous solutions. J. Colloid Interface Sci. 1997, 188, 415-422. [CrossRef]

43. Somasundaran, P. Reagents in Mineral Technology; Routledge: Abingdon-on-Thames, UK, 2018; ISBN 1351419625.

44. Bhagat, R.P. Kinetics of sodium dodecyl benzene sulfonate adsorption on hematite and its interaction with polyacrylamide. Colloid Polym. Sci. 2001, 279, 33-38. [CrossRef]

45. Tan, G.; Ford, C.; John, V.T.; He, J.; McPherson, G.L.; Bose, A. Surfactant solubilization and the direct encapsulation of interfacially active Phenols in mesoporous silicas. Langmuir 2008, 24, 1031-1036. [CrossRef] [PubMed]

46. Brunelli, A.; Pojana, G.; Callegaro, S.; Marcomini, A. Agglomeration and sedimentation of titanium dioxide nanoparticles $\left(\mathrm{n}-\mathrm{TiO}_{2}\right)$ in synthetic and real waters. J. Nanopart. Res. 2013, 15, 1684. [CrossRef]

47. Omar, F.M.; Aziz, H.A.; Stoll, S. Aggregation and disaggregation of $\mathrm{ZnO}$ nanoparticles: Influence of $\mathrm{pH}$ and adsorption of Suwannee River humic acid. Sci. Total Environ. 2014, 468, 195-201. [CrossRef] [PubMed]

48. Chowdhury, I.; Walker, S.L.; Mylon, S.E. Aggregate morphology of nano- $\mathrm{TiO}_{2}$ : Role of primary particle size, solution chemistry, and organic matter. Environ. Sci. Process. Impacts 2013, 15, 275-282. [CrossRef]

49. Han, Y.; Kim, D.; Hwang, G.; Lee, B.; Eom, I.; Kim, P.J.; Tong, M.; Kim, H. Aggregation and dissolution of ZnO nanoparticles synthesized by different methods: Influence of ionic strength and humic acid. Colloids Surf. A Physicochem. Eng. Asp. 2014, 451, 7-15. [CrossRef]

50. Gelabert, A.; Sivry, Y.; Ferrari, R.; Akrout, A.; Cordier, L.; Nowak, S.; Menguy, N.; Benedetti, M.F. Uncoated and coated $\mathrm{ZnO}$ nanoparticle life cycle in synthetic seawater. Environ. Toxicol. Chem. 2014, 33, 341-349. [CrossRef] [PubMed]

51. Lombi, E.; Donner, E.; Tavakkoli, E.; Turney, T.W.; Naidu, R.; Miller, B.W.; Scheckel, K.G. Fate of zinc oxide nanoparticles during anaerobic digestion of wastewater and post-treatment processing of sewage sludge. Environ. Sci. Technol. 2012, 46, 9089-9096. [CrossRef]

52. Ma, R.; Levard, C.; Judy, J.D.; Unrine, J.M.; Durenkamp, M.; Martin, B.; Jefferson, B.; Lowry, G.V. Fate of zinc oxide and silver nanoparticles in a pilot wastewater treatment plant and in processed biosolids. Environ. Sci. Technol. 2013, 48, 104-112. [CrossRef]

53. Rasool, K.; Lee, D.S. Effects of sulfidation on $\mathrm{ZnO}$ nanoparticle dissolution and Aggregation in sulfate-containing suspensions. J. Nanosci. Nanotechnol. 2015, 15, 7334-7340. [CrossRef]

54. Beltrán-Heredia, J.; Sánchez-Martín, J.; Solera-Hernández, C. Anionic surfactants removal by natural coagulant/flocculant products. Ind. Eng. Chem. Res. 2009, 48, 5085-5092. [CrossRef]

55. Stackelberg, P.E.; Gibs, J.; Furlong, E.T.; Meyer, M.T.; Zaugg, S.D.; Lippincott, R.L. Efficiency of conventional drinking-water-treatment processes in removal of pharmaceuticals and other organic compounds. Sci. Total Environ. 2007, 377, 255-272. [CrossRef] [PubMed]

56. Duan, J.; Gregory, J. Coagulation by hydrolysing metal salts. Adv. Colloid Interface Sci. 2003, 100, 475-502. [CrossRef]

57. Sousa, V.S.; Corniciuc, C.; Teixeira, M.R. The effect of $\mathrm{TiO}_{2}$ nanoparticles removal on drinking water quality produced by conventional treatment C/F/S. Water Res. 2017, 109, 1-12. [CrossRef] [PubMed]

58. Sun, J.; Gao, B.; Zhao, S.; Li, R.; Yue, Q.; Wang, Y.; Liu, S. Simultaneous removal of nano-ZnO and $\mathrm{Zn}^{2+}$ based on transportation character of nano-ZnO by coagulation: Enteromorpha polysaccharide compound polyaluminum chloride. Environ. Sci. Pollut. Res. 2017, 24, 5179-5188. [CrossRef] [PubMed]

59. Czech, B. Surfactants removal from water and wastewater using Co modified $\mathrm{TiO}_{2} / \mathrm{Al}_{2} \mathrm{O}_{3}$ photocatalysts. Ann. UMCS Chem. 2011, 66, 81-93. [CrossRef]

60. Inam, M.; Khan, R.; Park, D.; Lee, Y.-W.; Yeom, I. Removal of Sb(III) and Sb(V) by Ferric Chloride Coagulation: Implications of Fe Solubility. Water 2018. [CrossRef] 
61. Inam, M.A.; Khan, R.; Park, D.R.; Ali, B.A.; Uddin, A.; Yeom, I.T. Influence of pH and Contaminant Redox Form on the Competitive Removal of Arsenic and Antimony from Aqueous Media by Coagulation. Minerals 2018, 8, 574. [CrossRef]

62. Paton-Morales, P.; Talens-Alesson, F.I. Effect of ionic strength and competitive adsorption of $\mathrm{Na}^{+}$on the flocculation of lauryl sulfate micelles with $\mathrm{Al}^{3+}$. Langmuir 2001, 17, 6059-6064. [CrossRef] 